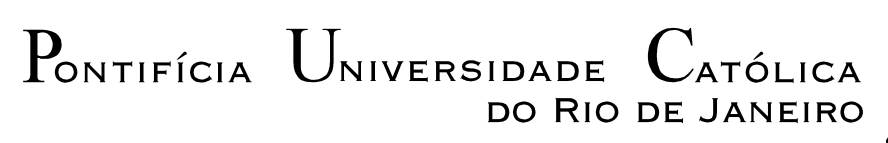

Oscar Enrique Miranda Castillo

\begin{abstract}
A real option model for valuing projects using implied binomial trees adjusted by project skewness and kurtosis
\end{abstract}

Tese de Doutorado

Thesis presented to the Programa de Pós-Graduação em Engenharia de Produção da PUC-Rio in partial fulfillment of the requirements for the degree of Doutor em Engenharia de Produção.

Advisor: Prof. Luiz Eduardo Teixeira Brandão

Co-advisor: Prof. Juan Guillermo Lazo Lazo

Rio de Janeiro

December 2017 


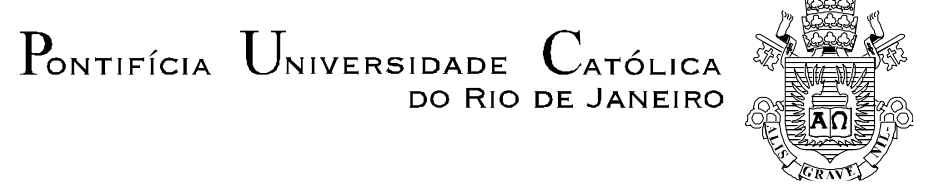

Oscar Enrique Miranda Castillo

\section{A Real Option model for valuing projects using implied binomial trees adjusted by Project skewness and kurtosis}

Thesis presented to the Programa de Pós-graduação em Engenharia de Produção of PUC-Rio in partial fulfillment of the requirements for the degree of Doutor em Engenharia de Produção. Approved by the undersigned Examination Committee.

Prof. Luiz Eduardo Teixeira Brandão

Advisor

Departamento de Administração - PUC-Rio

Prof. Juan Guillermo Lazo Lazo

Co-advisor

Departamento de Ingenieria - Universidad del Pacífico

Prof. Leonardo Lima Gomes

Departamento de Administração - PUC-Rio

Prof. Javier Gutiérrez Castro

VLT Carioca

Prof. Carlos de Lamare Bastian Pinto Instituto Brasileiro de Mercado de Capitais - Grupo IBMEC

Prof. Luiz de Magalhães Ozorio Instituto Brasileiro de Mercado de Capitais - IBMEC Educacional

Prof. Márcio da Silveira Carvalho Vice Dean of Graduate Studies Centro Técnico Científico - PUC-Rio

Rio de Janeiro, December 07th, 2017 
All rights reserved.

\section{Oscar Enrique Miranda Castillo}

The author graduated in industrial engineering from the science and engineering faculty of Pontificia Universidad Católica del Perú. He also has master degree in applied finance from Macquarie University, Sydney, Australia. The author has also experience in the finance and investment area.

Bibliographic data

Miranda Castillo, Oscar Enrique

A real option model for valuing projects using implied binomial trees adjusted by project skewness and kurtosis / Oscar Enrique Miranda Castillo; advisor: Luiz Eduardo Teixeira Brandão; co-advisor: Juan Guillermo Lazo Lazo. 2017.

72 f. : il. color. ; $30 \mathrm{~cm}$

Tese (doutorado)-Pontifícia Universidade Católica do Rio de Janeiro, Departamento de Engenharia Industrial, 2017.

Inclui bibliografia

1. Engenharia Industrial - Teses. 2. Avaliação de projetos. 3. Opções reais. 4. Mineração. 5. Árvore binomial. 6. Assimetria e curtose. I. Brandão, Luiz Eduardo Teixeira. II. Lazo Lazo, Juan Guillermo. III. Pontifícia Universidade Católica do Rio de Janeiro. Departamento de Engenharia Industrial. IV. Título.

CDD: 658.5 


\section{Acknowledgements}

I thank Professor Luiz Brandão, for accepting to guide my doctoral dissertation, for the teachings and support during the elaboration of this work. A special gratitude for my first tutor and friend, Carlos Patricio Samanez $(\dagger)$, who was a great influence for me.

I thank my co-supervisor Juan Lazo Lazo, who contributed with his comments and in many aspects, in the preparation of the dissertation.

CAPES, PUC-Rio, and PUCP for the aid granted, without which this work could not have been carried out.

I thank my parents, Inés and Oscar, my children, Grecia, Alonso and Alejandro; and my wife, Verónica, for her great support and love, which were fundamental to finish this work. 


\section{Abstract}

Miranda Castillo, Oscar Enrique; Teixeira Brandão, Luiz Eduardo (Advisor); Lazo Lazo, Juan Guillermo (Co-advisor). A real option model for valuing projects using implied binomial trees adjusted by project skewness and kurtosis. Rio de Janeiro, 2017. 72p. Tese de Doutorado - Departamento de Engenharia Industrial, Pontifícia Universidade Católica do Rio de Janeiro.

Valuation of capital investment projects is a difficult task for many companies, especially for those whose cash flows depend on commodity prices. The level of uncertainty in commodity prices has a significant impact in determining the proper timing for an investment. Traditional valuation methods, which do not take into account managerial flexibility or project uncertainty modeling can lead to non-optimal decisions. This research develops a dynamic model that considers these variables, and uses implied binomial trees adjusted by other indicators of risk, such as project return's skewness and kurtosis. The level of uncertainty can not only be measured by the project return's volatility, but also by how probable is the occurrence of a low or negative result in the project. The magnitude of this probability could be assessed by knowing the project return's skewness and kurtosis. To model the project's behavior, this dissertation presents two kinds of implied binomial trees, recombining and non-recombining trees. Each tree has its own specific approach to determining the value of the project, including options or managerial flexibility. An applied case is presented considering a mining project. The results suggest that the level of skewness helps to have a better measure of project risk, which combined with the real option approach, allows capturing the value of project managerial flexibilities; which is an important contribution of the proposed model in this dissertation.

\section{Keywords}

Valuation; real options; mining; non-recombining implied trees. 


\section{Resumo}

Miranda Castillo, Oscar Enrique; Teixeira Brandão, Luiz Eduardo; Lazo Lazo, Juan Guillermo. Um modelo de Opções Reais para avaliação de projetos ajustados por assimetria e curtose do projeto. Rio de Janeiro, 2017. 72p. Tese de Doutorado - Departamento de Engenharia Industrial, Pontifícia Universidade Católica do Rio de Janeiro.

A avaliação dos projetos de investimentos é uma tarefa difícil para muitas empresas, especialmente para aqueles cujo fluxo de caixa depende dos preços das commodities, já que o nível de incerteza nos preços tem um alto impacto na determinação do momento adequado para o investimento. Os métodos de avaliação tradicionais, que não levam em consideração a flexibilidade gerencial nem a modelagem da incerteza do projeto, podem levar a decisões não ótimas. Esta pesquisa desenvolve um modelo que considera estas variáveis, usando árvores binomiais implícitas ajustados por outros indicadores de risco, como assimetria e curtose da rentabilidade do projeto. O nível de incerteza pode não só ser medido pela volatilidade do retorno do projeto, mas também pela probabilidade de se obter um resultado baixo ou negativo no projeto. A magnitude dessa probabilidade poderia ser a avaliada conhecendo-se o valor da assimetria e curtose do retorno do projeto. Para modelar o comportamento de um projeto, esta dissertação apresenta dois tipos de árvores binomiais implícitas, recombinantes e não recombinante. Cada árvore tem sua própria abordagem específica para determinar o valor do projeto, incluindo opções. Um caso aplicado é apresentado considerando uma empresa de mineração. Os resultados sugerem que o nível de assimetria contribui para uma melhor avaliação do risco do projeto, que combinado com a metodologia de opções reais captura melhor o valor das flexibilidades do projeto; o que é uma importante contribuição do modelo proposto nesta dissertação.

\section{Palavras-chave}

Opções Reais; árvore binomial; avaliação de projetos; mineração; assimetria; curtose. 


\section{Table of contents}

1 Introduction 10

$\begin{array}{ll}1.1 \text { Motivation } & 10\end{array}$

1.2 Objectives 11

1.3 Disertation description 12

1.4 Contributions 14

$\begin{array}{lr}1.5 \text { Dissertation organization } & 16\end{array}$

2 Literature Review $\quad 17$

3. Methodology 22

3.1 Methodology Description 22

3.2 A Recombining binomial tree model 23

3.3 A Non -Recombining binomial tree model 25

3.4 Methodology development 26

3.4.1 Building a recombining binomial tree 32

3.4.2 Building a non- recombining binomial tree 39

4. Application 44

4.1 Applied model to a recombining binomial tree 47

4.2 Applied model to a non -recombining binomial tree 51

4.3 Applied case using the traditional CRR binomial tree. 61

5 Conclusions $\quad 65$

$\begin{array}{ll}\text { 6. References } & 69\end{array}$

$\begin{array}{ll}\text { 7. Annexes } & 72\end{array}$ 


\section{Table list}

Table 1: List of variables 45

Table 2: Intial project value without options $\quad 46$

Table 3 : Recombining binomial tree - Initial nodal probabilities 48

Table 4 : Adjusted nodal probabilities by Skewness and kurtosis 49

Table 5 : Simulated project value with adjustments 49

Table 6 : Project values with option to expand 50

Table 7 : Project values with option to abandon $\quad 50$

Table 8 : Project value with options to abandon and expand 51

Table 9 : Project parameters for each year 51

Table 10 : Project value with option to expand - CRR 62

Table 11 :Project value with option to abandon - CRR 62

Table 12 : Project value with option to abandon and expand - CRR 62

Table 13: Comparsion of project values $\quad 63$ 


\section{Figure list}

Figure 1 : Liquidated Junior Mining ETF 11

Figure 2 : A recombining binomial tree (RBT) 33

Figure 3: Project expected value $\quad 34$

Figure 4 : Project return parameters using CA methodology 35

Figure 5 : Project return parameter using BHD methodology 36

Figure 6 : Non-recombining binomial tree (NRBT) 40

Figure 7: Simulated project expecte value $\quad 41$

Figure 8 : Historical daily prices of minerals 44

Figure 9 : Project expected value in year 5 without options 47

Figure 10 : Project return parameters in a RBT 47

Figure 11 : Initial recombining binomial tree 48

Figure 12 : Project return parameters in a NRBT 52

Figure 13 : Project value without options 53

Figure 14 : NRBT - initial nodal probabilities $\quad 54$

Figure 15 - Adjusted nodal probabilities

Figure 16: New path probabilities $\quad 56$

Figure 17: Simulated project value with adjustments 58

Figure 18 - Project value with option to expand 59

Figure 19 - Project value with option to abandon 60

Figure 20 - Project value with option to abandon and expand 61 


\section{1 \\ Introduction}

This dissertation develops a methodology to evaluate projects in industries where there is a high level of uncertainty and flexibility, such as mining and agro industrial projects. The proposed method can be also a complementary and useful tool to value other types of projects, especially those exposed to commodity prices. Most of valuation models are done taking into consideration that assets returns are normally distributed, which is not entirely true. In this dissertation a methodology is presented to evaluate projects whose return may be not normally distributed, which means it has certain level of skewness, and a kurtosis value greater than three.

\section{1}

\section{Motivation}

The motivation for this dissertation is to develop a valuation methodology that incorporates variables that are not considered in traditional methods, such as non-constant volatility, managerial flexibility and analyst criteria, using implied binomial trees. Binomial tree methods are easily constructed and understandable. In fact, it is well know the use of recombining binomial trees to value different assets and derivatives; however most of them consider constant volatility. In this dissertation a non-recombining implied binomial tree model is proposed to value projects, for instance a project with non- constant volatility could be assessed. This approach is more realistic if it is considered that the risks change for different reason during project lifetime. As an example, figure 1 shows the historical prices of a Junior Mining ETF fund that has to be liquidated for lack of liquidity. The risk involved in junior mining projects change significantly in their lifetime because of several variables, and the valuation process is commonly done without considering neither project volatility nor managerial flexibility. 


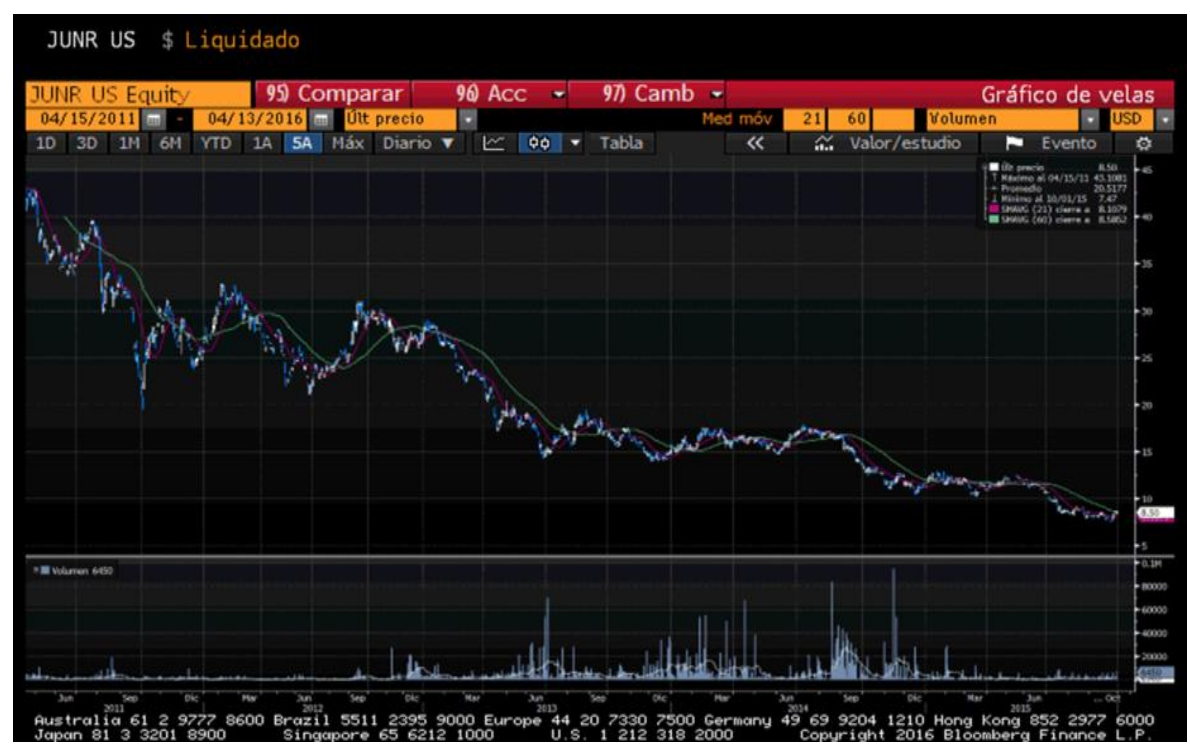

Figure 1 : Liquidated Junior mining ETF

Source: Bloomberg

Another motivation of this dissertation is to present a simple methodology in which Real Options Theory (ROT) can be used for the valuation of a firm or a project. It is well known that ROT is very useful to value managerial flexibility. As the value of a project depends on the cash flows generated by its real assets and embedded options it may have, it would be logical to think that it is possible to use ROT to determine their fundamental value. However, ROT is not commonly used by practitioners because of its complexity and difficulty to solve and show the valuation problem in a simple way.

Implied binomial trees are used because of their simplicity to model asset behavior and obtain project valuation. An advantage of binomial tress is that is visually simple to understand. For instance, another motivation is to present in a simple and practical way the use of binomial trees allowing for uncertainty under a constant and non-constant volatility scenario.

\section{2}

\section{Objectives}

As mentioned, the methodology proposed is innovative and different. It contributes to develop a valuation method using implied changing volatility, 
skewness and kurtosis as other indicators of risk, and incorporates managerial flexibility through the use of ROT in the project valuation.

This work pretends to achieve the following objectives:

- To develop a valuation method for projects that incorporates managerial flexibility, non-constant volatility and analyst criteria bases on a risk reward approach. The model is proposed for projects whose returns are not normally distributed. Flexibility arises in any project that has uncertain scenarios; and it is possible to quantify this flexibility using ROT. Projects have their own volatility, however sometimes it depends from other assets which can be traded or not. Using project's volatility and non-recombining implied binomial trees adjusted by the Gram Charlier expansion, this work is including variable volatility and analyst criteria based on risk analysis.

- To obtain a valuation methodology that can be used as a practical tool in any industry. In fact, future works can combine other variables, including costs, to develop a general valuation method. Other options, different from the ones used in this work, also could be considered to add more flexibility to our valuation problem.

\section{3 \\ Dissertation Description}

This work proposes an innovative valuation method that considers, as indicators of risk, the level of skewness and kurtosis of the project returns from simulated future project values. These future values are determined using constant and non-constant volatility. The model proposes the Gram-Charlier expansion to construct an implied combining and non-recombining tree, and it allows the use of ROT to assess project feasibility incorporating managerial flexibility.

Most of the traditional valuation methods do not consider this flexibility and therefore, inaccurate results may be obtained. Managers are always taking decisions that should consider these variables because they could have an impact on project valuation. This work use Real Options Theory (ROT) to incorporate flexibility in project valuation. 
Real options theory (ROT) is an approach that complements traditional capital budgeting methods, such as the Discounted Cash Flow (DCF). This method considers the options that a project may have over certain assets, and allows the company to incorporate these managerial flexibilities, which may provide or generate value and which are not captured by traditional methods, into its pricing model.

Real Options theory (ROT) evolved from the seminal work of Black and Scholes (1973) and Merton (1973) in pricing financial options, and its application to the valuation of options over real assets was proposed in the works of Tourinho (1979), McDonald and Siegel (1986), Dixit and Pindyck (1994) and Trigeorgis (1996).

The use or ROT presents many advantages. First, the weakness in the discounted cash flow (DFC) method, which is the tool most commonly used in valuation, but does not adequately value uncertainty and flexibility which are inherent in investment projects. The lack of analysis of this factor has led many companies to make wrong decisions, especially in mining projects in emerging countries whose growth depends largely on this sector. Using ROT is an appropriate way to consider uncertainty and managerial flexibility in a valuation process.

Second, the ROT has been more accessible to a wider public since the last twenty years. Efforts have been made to show how ROT can be applied for valuing projects or assets in general. Although ROT encompasses some sophisticated calculus, some empirical research based in companies interviews show that ROT is being used as strategic way of thinking, an analytical valuation tool and an organization -wide process for evaluating, monitoring, and managing capital investments (Triantis and Borison 2001). In fact, a ROT approach is preferred in some industries where large investments and uncertain returns are more probable, like oil and gas, mining and life science for example. All this has created awareness for evaluating investment projects with a real options approach and has shown its advantages over other tools and traditional methods.

Third, the extreme volatility of the risk factors and the greater flexibilities the projects in a current changing environment require a sophisticated and more accurate assessment modeling of these factors (Myers, 1977).

Trigeorgis (1996) published a detailed summary of valuation methods using real options, which can be used in practice. The main tool he applied to the valuation 
of real options is the traditional binomial tree of Cox-Ross-Rubinstein (CRR, 1979). However, using traditional binomial tress assumes a constant volatility during the period analysis and are forward constructed. This work proposes a method to construct an implied binomial tree using constant and non-constant project return's volatility.

Since a hypothetical mining project is assessed in this dissertation to show an application of the proposed model, the uncertainty will be generated by metal prices and their level of correlation between them only. The two metals considered are copper and molybdenum. Regarding the real options the project has, two options are considered: the option to expand and abandon the project, separately and combined as well.

In this dissertation a model for the cash flow of the company is developed, and it is specifically determined its growth and value at any time. According to the considered variables, such as commodity prices, implied volatility, convenience yield and some others, a project value equation is determined. The project value is then arrived at using Monte Carlo simulation.

When applying a recombining tree, the project behavior is modeled using the traditional CRR (1979) tree, and the implied tree is constructed according to Jackwerth (1994). In order to add some analyst criteria a function of weigh is added, like in Lim and Zhi (2002), to find probabilities along the tree.

When applying a non-recombining tree, the project behavior is modeled using Monte Carlo simulations for each period of analysis. The probabilities along the tree are obtained from variable volatility, and they different in each period.

\section{4}

\section{Contributions}

An important contribution of this dissertation is the proposed model; which allows to asses project feasibility considering others indicators of risk, such as project return's skewness and kurtosis, which are not considered in other known valuations methods such as standard binomial trees as the one developed by CRR 
(1979). The use of these indicators to evaluate projects are no mentioned in any valuation method or literature consulted by the author, and are important in order to have a better understanding of risk for management purposes. When project's return present a skewness value greater than zero, meaning that returns are not actually normal distributed, negative future values or negative net present values are more probable for example. For instance it is better to adjust the project return probability distribution for its level of skewness and kurtosis applying the GranCharlier expansion. This adjustment will allow a better approach to model project behavior when incorporating the embedded options.

Another important contribution of this dissertation is the methodology developed to construct the proposed model. In this research, there is a combination of some tools and theories, such as real options and implied binomial trees, which are barely combined to evaluate projects. In fact, the model proposed uses a nonconstant volatility in implied binomial trees to model project values, incorporating managerial flexibility, which is more appropriate to have a more realistic situation approach over project risks. The use of implied trees allows the project's volatility to be treated in a more appropriate way, as this volatility is not the same as that of the underlying asset or commodity that influences the cash flow of the project. By other side, the use of implied binomial trees allows to incorporate some weight to path probabilities which is an advantage because allows to include some criteria based on market information analysis for example.

On the other hand, when using non constant volatility, a non-recombining tree has to be constructed. Using non-recombining trees not only allows to model project value with changing volatility, but also allows to use the level of skewness and kurtosis as indicators of risk in each period of the binomial tree for a decision making process. For instance, a powerful tool of analysis can be obtained when we combine implied binomial trees and considering the real options the project has.

The general binomial tree approach developed by Jackwerth (1994) will be used because through the methodology proposed by the author is possible to incorporate some flexibility, such as the judgment of the analyst considering some likely scenarios. Although this methodology was proposed for assets with constant volatility, and for instance for recombining implied binomial trees, in this 
dissertation it is developed a methodology that uses project's return skewness and kurtosis, which in this case are constant, to adjust probabilities along these trees, to have a more accurate analysis of project risks. This is another important contribution of this dissertation.

\section{5}

\section{Dissertation organization}

This dissertation is organized as follows. After this introduction, in Chapter two we present a review of the literature. In Chapter 3 the methodology proposed is described followed by an application and results in chapter 4 . The conclusions are presented in Chapter 5. 


\section{2 \\ Literature Review}

Valuation of investment projects, especially those who depends on variables with high volatility, has been a difficult task for companies. The most common method used to value any project is the Discounted Cash Flow (DCF) method, which assesses the project's revenues tendency considering an adjusted discount rate, but does not capture the value of any managerial flexibility that may be embedded in the project, and thus, may lead to undervaluation of the project. Managerial flexibility has option-like characteristics, and can only be value using option pricing methods, such as the Real Options Analysis (ROA). As noted by some authors, the use of ROA in intensive capital investment projects can be more accurate and useful for the decision making process. (Dimitrakopoulos \& Abdel Sabour, 2007; Dixit \& Pindyck, 1994; Mardones, 1993; Moyen, Slade, \& Uppal, 1996).

Real Options Analysis (ROA) has become an important tool to model and determining the value of managerial flexibility in natural resources projects and in the industry (Dixit \& Pindyck, 1994; Godinho, 2006; Koushavand, Askari-Nasab, \& Deutsch, 2014; Martinez, 2012; Trigeorgis, 1996).Tourinho (1979) is deemed as the pioneer in the application of the option pricing methods developed by Black and Scholes (1973) and Merton (1973) to real assets. In the following years, Brennan and Schwartz (1985) showed how to value a natural resource project using ROA.

In fact, one of the first analyses done on natural resources projects using ROA, particularly in a real mining project was done by Kelly (1998), which was based on a single gold mining project, the Lihir Gold Limited, situated on Lihir Island, Papua New Guinea. The paper developed an option valuation framework considering operational flexibility to determine de value of a discovered project relying only in its gold reserves. Using the binomial method, the author examines the time developing option.

Further research on the application of ROA to mining ventures was made by Slade (2001), who created a model to assess the value of managerial flexibility considering price data, costs, grades, reserves, ore extraction, and metal out for 
twenty one Canadian cooper mines. The conclusion was that values of real projects can vary substantially according to the stochastic process which is assumed for the data. Projects where the Geometric Brownian Motion (GBM) was used to model the stochastic diffusion process were valued at almost twice the value of projects where a Mean Reversion Model (MRM) was used. For these reason, option values under GBM processes were valued at almost ten times as those under MRM, which was attributed to the life time of real projects. The authors concluded that one of the reasons that real option theory is not used for practical decisions is due to the lack of real and more accurate data.

Moel and Tufano (2002) analyzed the option to temporarily shut down a gold mine in response to output prices. They assessed statistical evidence of 213 gold mines that were shut down at least once from 1988 to 1997 in USA. They conclude that this managerial flexibility, the option to temporarily suspend production of a mine, is used frequently in the industry, especially when gold prices are not favorable.

Shafiee, Topal, and Nehring (2009) developed a model to calculate the production rates that maximize the mining project value in certain periods of time. They applied their model to a zinc mining company (Century Mine) located in Queensland, Australia; and used a ROA considering the option to close and reopening the mine according to zinc prices. The authors also presented extensive empirical evidence of the use of ROA and DCF in operating non-renewable commodities, mostly mining projects. Haque, Topal, and Lilford (2014) used real options theory to value a hypothetical gold mine considering deferral, temporary close and abandon options. They use a GBM process to model gold prices and noted the great importance of its volatility on project's value.

Ajak and Topal (2015) applied real options theory to decision making on the operational level in a mining project and evaluate a project considering an option to switch between different pits using binomial trees. Inthavongsa, Drebenstedt, Bongaerts, and Sontamino (2016) applied a real option framework to value managerial flexibility on open pit mining projects. They evaluated a hypothetical gold mine considering options to defer the investment, expand, maintain and shut down the mine. They used System Dynamics (SD) to model and calculate the value of these options and concluded that a real option framework is 
more consistent than a simple discounted cash flow method to value mining investments. They also concluded that managerial flexibility increases value on mining projects and the best way to determine this value is through ROA. There are several other studies, such as Mardones (1993), Frimpong and Whiting (1997) and Humphreys (1996) shown how ROA can be more appropriate to value mining investments.

There are many uncertainties that can affect investment decisions in mining projects. Some of these uncertainties, such as metal prices, can be modeled using stochastic processes that mimic their behavior over time. Stochastic processes can be defined as variables that evolve in discrete or continuous time in a way that is partially unpredictable, or random. The behavior of metals prices can be assumed to follow a Geometric Brownian Motion (GBM) (Brennan \& Schwartz, 1985; McDonald \& Siegel, 1986), especially during short periods of time. When it is appropriate to assume that metal prices tend to revert to a long-term average, a Mean Reverting Movement (MRM) may be more appropriate to model this price behavior (Ozorio, Bastian-Pinto, Baidya, \& Brandão, 2013). The selection of stochastic process is important since it has a direct impact on the value of any real options associated with the project. It also influences directly in the economic evaluation of the project and the investment decision. Some authors consider both a GBM and MRM in a two factor model to evaluate the behavior in the long and short term respectively (Gibson \& Schwartz, 1990; E. Schwartz \& Smith, 2000; E. S. Schwartz, 1997). Dixit \& Pindyck (1994) even argue that it is impossible to reject a GBM for certain commodities, such as metals, for a period less than 30 years. In this dissertation a sample of prices for a period of three years is used.

One of the most used valuation tool is the binomial tree. The well-known Cox, Ross \& Rubinstein tree (CRR, 1979) is widely used because its construction is simple and easy to understand. This tree assumes that the asset follows GBM with a constant volatility, however according to market data for liquid assets, this is not the case since it contradicts volatility smile. For this reason, recent literature suggests using implied market volatility to construct implied binomial trees for pricing securities. 
Implied binomial trees are a good tool to model the behavior of a stochastic variable when the probability distribution that follows this variable is known. In this dissertation, the $\mathrm{CF}$ is the variable, the stochastic process for the $\mathrm{CF}$ is assumed to be a GBM, and its probability distribution function is lognormal. In fact, the model is developed to determine the value that would have with or without options at any given time, especially in the time when involved real options would apply.

One of the best known IBT was proposed by Rubinstein (1994). It proposes the construction of the tree from the asset's final values according to their probability distribution. However, a major weakness of this model is that it assumes that all paths are equally likely. Jackwerth (1997) proposes the construction of a generic binomial tree, based on a function that determines a different probability for some paths of the tree. This approach allows incorporating non-constant volatility during the construction of the tree. Derman and Kani (1994) introduced the construction of an alternative binomial tree going forward, rather than using the final value as a starting point. These authors proposed that market prices of options were taken as future values for a specific expiration date, and taking the value of the strike of these options to determine actual price of the asset, thus making it possible to incorporate options with different maturity dates. The problem is that an extensive interpolation is required to find the best needed options. On the other hand, negative probabilities may appear in this tree. To resolve this problem, Cakici and Barle (1998) proposed an improvement to the model of Derman and Kani (1994), they proposed that the central nodes of the tree be aligned with futures prices, instead of the current prices. Barle and Cakici (1998) proposed finding the value of options using the Black Scholes formula instead of using the binomial tree. The binomial tree of Barle and Cakici (1998) is a very good alternative to model future prices, however suffers from some violations of arbitrage (negative probabilities), in a lesser extent than the model proposed by Derman and Kani (1994). A detailed description of the matters mentioned above, as well as other nonparametric methods can be found in Jackwerth (1999).

As noticed by Charambous et al. (2007), all the mentioned implied binomial trees are constructed following a diffusion process on a recombining binomial tree, which generates interdependence between nodes. To solve this problem the authors 
propose constructing implied non-recombining trees. They propose a methodology for calibrating a non-recombining binomial based on optimization. Specifically, the authors minimize the difference between observed market prices and the theoretical underlying asset values for each node.

Another important reference for this work is the paper of Mark Rubinstein (1998) where he proposes to adjust a standard binomial density into a unimodal standardized discrete density with a prespecified skewness and kurtosis. In this dissertation is used these indicators to adjust the implied non recombining tree but considering the current kurtosis and skewness for the probability distribution of the firm value in each node.

In this dissertation a forward non-recombining tree is built as the initial future values for the firm. Later, an implied non-recombining tree is deduced adjusting path probabilities using the Gram-Charlier expansion based on certain indicators of risk (Skewness and Kurtosis) for the probability distribution of the company value in each node. The Gram-Charlier expansion is chosen because allows to adjust assets returns with a leptokurtic probability distribution, which means it has a kurtosis value greater than 3. Empirical evidence and research shows that assets return are more probable to be leptokurtic as it is mentioned by Choi and Nam (2008), Joundeau and Rockinger (2003), and Mittnik et al (2000). 


\section{3. \\ Methodology}

\section{1 Methodology Description}

This dissertation proposes a general methodology to assess project feasibility taking in consideration project uncertainty and managerial flexibility. The level of uncertainty will be evaluated not only considering project volatility but also project return asymmetry. The methodology begins by modeling the free cash flow of the firm. The variables that determine the cash flow generated by the project are defined initially. In this dissertation, a two factor model is developed and they will determine firm revenues. The factors could be any variable whose price is determined by market offer and demand. These factors are considered stochastic and they could be the prices of two minerals, agricultural products, energy commodities or any other product the company can produce and commercialize. It could be possible to consider the production cost as a stochastic variable as well; however this variable is considered as a constant percentage of sales in this dissertation. Later on, this work can be extended to three factor model, in which the production cost can be included.

Once the cash flow equation is determined and its parameters are identified, the initial firm expected value is found considering an initial free cash flow and its respectively growth per year. From this point forward, the future project values are modeled and determined using Monte Carlo simulations for each year of analysis. Each year, the project will have different expected values, which will depend on project return volatility. These expected values could resemble an underlying financial asset without options; or without managerial flexibility if we talk about a real asset, such as a project. These values would be similar to strike prices in financial options. This means that for any real asset with options, such as project, any managerial flexibility could be valued if it is considered to be applied each year, as an American option. In this dissertation the option to expand and abandon are assessed, and the valuation of these options will be done at the initial time, which means time zero.

After obtaining project values for each year, the annual project return is calculated using Monte Carlo simulations. The annual project return will be 
calculated as the percentage of value increased or decreased from year zero to any other year. For example, the annual project return for the first two years will be square root of the project growth from year zero to year two. In this way, it could be possible to find an average annual return from year zero to year five for example. It can also be found an expected volatility for the annual return, which could be considered constant during project life. In fact, these parameters are modeled and found using Monte Carlo simulations.

The proposed model in this dissertation also considers the possibility of having a yearly return and volatility. This means to analyze project growth from one year to the following year. For example, the annual project return from year two to year three will be the percentage of value increased from year two to year three. This means that there will be different annual returns and volatilities. In this case the project will present a non-constant volatility during the timeframe evaluated.

As suggested lines above, the variable to analyze will be the project return. In fact, thanks to the simulations other project return parameters are found, such as project return volatility, skewness and kurtosis.

Once the parameters are defined, the project value can be modeled using binomial trees. This dissertation proposes the use of binomial trees because of its simplicity to show how managerial flexibility can be captured through real options theory; and also due to its suitability to incorporate several options during project life, which can be exercised at any moment. This work presents two types of binomial trees:
a. Recombining binomial trees
b. Non-recombining binomial trees

Both trees are adjusted by volatility and certain level of skewness and kurtosis.

\section{2}

\section{A Recombining binomial tree model}

When using recombining binomial trees, constant volatility is assumed for project return. Therefore, project value behavior can be modeled considering a constant risk neutral probability along the binomial tree. The steps to apply for the proposed methodology are: 
1. To obtain the project value equation.

2. To define project initial value and its parameters of growth, volatility, skewness and kurtosis

3. To build a standard recombining binomial tree to model project value, and adjust final nodal probabilities through the Gram-Charlier expansion, which considers project return skewness and kurtosis

4. To build an implied binomial tree adjusting nodal probabilities by a function of weight. This is done to incorporate the analyst criteria

5. To incorporate embedded options along the binomial tree and obtain the project value considering these flexibilities

Once the project's fundamental initial value (expected value in time zero) is found, the process of building the implied recombining binomial tree starts. The first step is to build a standard recombining binomial tree in order to find the project expected values on the final nodes of the tree. At the same time, the final nodal probabilities are calculated for each project expected value, considering the same risk neutral probability along the tree.

Using the Gram-Charlier expansion, the probability distribution of these final expected values is adjusted according to its skewness and kurtosis. These parameters are considered as indicators of risk for taking an investment decision. For example, when the probability distribution has a positive skewness it would be an indicator of high project values are less probable than low project values. On the contrary, when the skewness is negative, high project values are more probable than low project values. Taking in consideration these parameters, a manager could asses and measure the risk involved in his investment decision process. For the valuation model presented in this dissertation, the skewness and kurtosis depends on project return volatility, which actually measures project growth variability.

As seen in Jackwerth (1994) and also in Lim and Zhi (2001), a standard binomial tree can be fully constructed by a given ending-node probability and a linear weight function. Similarly, an implied binomial tree can be fully described 
by an arbitrary ending probability distribution and the same linear weigh function. The same principle is applied for the recombining implied binomial tree in this part. By doing this, more information can be added in the tree, such us the information processed by an analyst. This information will be incorporated to assign different nodal probabilities in the preceding nodes. In a recombining binomial tree, the nodal probabilities depend on path probabilities, since there is more than one path to reach each node. Then a recombining implied binomial tree is build considering different nodal probabilities that are obtained from a percentage or weigh given to each path.

After building the recombining implied binomial tree, managerial flexibility is incorporated in the project to find the firm value under a real option approach. Embedded options are considered for each period of time, and the valuation is done applying risk neutral probabilities, such as is done in traditional binomial trees.

\section{3}

\section{A Non -Recombining binomial tree model}

When the model applies a non-recombining tree, the volatility changes each period. However, it would be constant during each time interval. This approach requires the use of different risk neutral probabilities for each period to obtain project values using binomial trees. The steps followed to apply this method are mention below:

1. Determine the value equation of the project.

2. Define the project's initial value and its parameter of growth, volatility, skewness and kurtosis for each period of time

3. Build a non-recombining binomial tree to model project value, and adjust each nodal probabilities for each period by its respectively kurtosis and skewness using the Gram-Charlier expansion.

4. Build an implied non- recombining binomial tree

5. Consider the embedded options along the binomial tree, and obtain the project value considering these flexibilities 
Once the fundamental values (expected values) are found for each period of analysis, the parameters of growth, volatility, skewness and kurtosis are determined for each period. Taking the initial project value, a non-recombining binomial tree is constructed considering the different volatility values for each period.

Using the Gram-Charlier expansion, the probability distribution of these values is adjusted according to its skewness and kurtosis in each period. As mentioned before, these parameters are considered indicators of risk and can give an idea of what are the probabilities of having high o lover project values or returns.

In this particular case, the assessment is done for each year, which is quite different from the previous case, when volatility is consider constant during the whole project life.

Once nodal probabilities are adjusted, an implied binomial tree is constructed and options are incorporated along the tree.

After building the non-recombining implied binomial tree, managerial flexibility is incorporated in the project to find the firm value under a real optic approach.

\section{4 \\ Methodology development}

Decisions to invest in projects are affected by many uncertainty factors throughout his entire life. Some of these factors, especially commodity prices, can be modeled using stochastic processes to describe their behavior over time. In this work, a two factor model is developed. These factors could be any commodity whose could be modeled.

Stochastic processes can be defined with variables that evolve in discrete or continuous time in an unpredictable or partially random way. For example, the behavior of metals prices can be evaluated considering that they follow a Geometric Brownian Motion (GBM) (Brennan \& Schwartz, 1985; McDonald \& Siegel, 1986) especially in short periods of time. Some developed studies, like Dixit \& Pindyck (1994), showed that a GBM is the most convenient process to model the behavior of commodity prices. There are other models that consider metals have a long-term average price and a Mean Reversal Movement (MRM) is more appropriate to evaluate their price behavior (Ozorio et al, 2013). The selection of the stochastic process is very important since it has a direct impact on the behavior of the real 
options associated with the project. It also influences directly in the economic evaluation of the project to take investment decisions.

Other authors combine both processes, generating models that can explain the behavior of the price considering its evolution in the short and long term. Some authors suggest considering a GBM and MRM to evaluate the behavior in the long and short term respectively (Gibson \& Schwartz, 1990; Schwartz \& Smith, 2000; Schwartz, 1997).

Since the evaluation period is short (less than ten years), a GBM will be used to model the stochastic diffusion prices process of two commodities. In order to validate this assumption, an Augmented Dickey Fuller Test (ADF) (1979) Test will be done to verify that the prices of the selected commodities follow a GBM. The results for this test will be shown in the application chapter.

The variable to model is the cash flow $(C F)$ of the project. The variables that impact the $\mathrm{CF}$ are the prices of the two produced and commercialized commodities. It will be assumed that these prices follows a GBM. The cost of production will be considered constant, and will be a percentage of revenues. The CF function then is determined by equation (1).

$$
C F_{t}=(1-T) \times(1-G) \times\left[P \times C_{t}+Q \times M_{t}\right]
$$

Where:

$C F(t)$ : Free cash flow at time $t$

$P$ : constant production of commodity one, in metric tons $(M T)$.

$Q$ : constant production of commodity two, in metric tons (MT).

$C(t)$ : price of a $M T$ of commodity one time $t$

$M(t):$ price of $M T$ of commodity two at time $t$

$T$ : income tax rate

$G$ : Percentage that represents the weighted cost of production.

The tax $(T)$, the weighted cost of production $(G)$, and amounts of metric tons of commodity one $(C)$ and commodity two $(M)$ produced, are considered 
constant in this model. This is consistent in the sense that, in practice, these variables are either established or controlled by the company. In this model is not considered a fixed cost since it is included in the weighted cost or production as a percentage. This is an assumption in the proposed equation.

Since $C$ and $M$ follow a GBM process, their diffusion process can be defined by equations (2) and (3):

$$
\begin{aligned}
& d C=\left(u_{c}-y_{c}\right) C d t+C \sigma_{c} d w_{c} \\
& d M=\left(u_{m}-y_{m}\right) M d t+M \sigma_{m} d w_{m}
\end{aligned}
$$

where $d w_{c}$ and $d w_{m}$ are variables following a Wiener process, $\sigma_{c}$ and $\sigma_{m}$ are volatilities of commodity prices yields, and $u_{c}, u_{m}$ are the average growth rates of the two commodity prices. By other side, $y_{c}$ and $y_{m}$, are the convenience yields of commodity one and two respectively; and $\rho$ is the correlation between both commodity prices.

The variable $\mathrm{R}$ is defined as the natural logarithm of $C F$ generated at time $\mathrm{t}$

$$
R=\operatorname{Ln}\left(C F_{t}\right)=\operatorname{Ln}\left\{(1-T) \times(1-G) \times\left[P \times C_{t}+Q \times M_{t}\right]\right\}
$$

Since $T$ and $G$ are constants, it can be expressed the value of $K$ as $K=(1-T) \times(1-G)$, and our final equation for our variable $\mathrm{R}$ is shown in equation (5):

$$
R=L n C F_{t}=\operatorname{Ln} K+\operatorname{Ln}\left[P C_{t}+Q M_{t}\right]
$$

To define the diffusion stochastic process $(d R)$ followed by our variable $\mathrm{R}$, the Ito's Lemma (1951) is applied according to equation (6): 


$$
d R=R_{t} d_{t}+R_{c} d c+\frac{1}{2} R_{c c} d c^{2}+R_{m} d m+\frac{1}{2} R_{m m} d m^{2}+R_{c m} d c d m
$$

Applying the first and second partial derivatives in equations (2) and (3), and substituting in equation (6) the following expression is obtained:

$$
\begin{aligned}
d R= & \left\{\frac{P C}{(P C+Q M)}\left(u_{c}-y_{c}\right)+\frac{Q M}{(P C+Q M)}\left(u_{m}-y_{m}\right)-\frac{1}{2}\left[\frac{(P C)^{2}}{(P C+Q M)^{2}} \sigma_{c}^{2}+\frac{(Q M)^{2}}{(P C+Q M)^{2}} \sigma_{m}^{2}+2 \frac{P C Q M}{(P C+Q M)^{2}} \sigma_{c} \sigma_{m} \rho\right] d t\right. \\
& +\frac{P C}{(P C+Q M)} \sigma_{c} d w_{c}+\frac{Q M}{(P C+Q M)} \sigma_{m} d w_{m}
\end{aligned}
$$

Where :

$$
\frac{P C}{(P C+Q M)}=R_{c}=x_{c} ; \text { corresponds to the percentage share of commodity one }
$$

sales

$\frac{Q M}{(P C+Q M)}=R_{m}=x_{m} ;$ corresponds to the percentage share of commodity two sales

The expression for any variation of $d R$ may be based on the percentage of sales of each commodity:

$$
d R=\left\{\begin{array}{l}
x_{c}\left(u_{c}-y_{c}\right)+x_{m}\left(u_{m}-y_{m}\right)- \\
\frac{1}{2}\left[x_{c}^{2} \sigma_{c}^{2}+x_{m}^{2} \sigma_{m}^{2}+2 x_{c} x_{m} \sigma_{c} \sigma_{m} \rho\right]
\end{array}\right\} d t+x_{c} \sigma_{c} d w_{c}+x_{m} \sigma_{m} d w_{m}
$$

The term for $d R$ is convenient because everything depends on the growth trend of commodity prices and their participation in company sales. It is important to notice that the probability distribution for $d R$ is normal since represents the cash flow return obtained from two commodities whose prices follows a GBM .

From equation (1), and considering that the cash flow follows a GBM as inferred by the normal distribution of $d R$, the expected cash flow can be determined at any time $t$, according to the equation (9):

$$
C F_{t}=K \times C F_{t-1} e^{d R}
$$

The expected value for the project can be determined as follows: 


$$
E(V)=K \int_{0}^{t} E\left(C F_{t-1} e^{d R}\right) e^{-(\alpha-\partial) t} d t
$$

Where
$\alpha$ : risk adjusted discount rate
$\partial$ : dividend yield.
$t$ : project life time

And considering that the an initial cash flow $C F_{0}$ is known, then the expected value can be calculated through equation (11)

$$
E(V)=K \int_{0}^{t} C F_{0} E\left(e^{d R}\right) e^{-(\alpha-\partial) t} d t
$$

Since $d R$ follows a normal distribution, the expected value for: $E\left(e^{d R}\right)=e^{E(d R)}$; then $\mathrm{E}(d R)$ for any interval $d t$ according to equation (8) is as follows:

$$
E(d R)=\left\{x_{c}\left(u_{c}-y_{c}\right)+x_{m}\left(u_{m}-y_{m}\right)-\frac{1}{2}\left[x_{c}^{2} \sigma_{c}^{2}+x_{m}^{2} \sigma_{m}^{2}+2 x_{c} x_{m} \sigma_{c} \sigma_{m} \rho\right]\right\} d t
$$

The variable $A$ is stated to replace the deterministic expression obtained in equation (12), as follows:

$$
A=x_{c}\left(u_{c}-y_{c}\right)+x_{m}\left(u_{m}-y_{m}\right)-\frac{1}{2}\left[x_{c}^{2} \sigma_{c}^{2}+x_{m}^{2} \sigma_{m}^{2}+2 x_{c} x_{m} \sigma_{c} \sigma_{m} \rho\right]
$$

Replacing $A$ in equation (11), the $E(V)$ of the project at any time $t$ can be obtained by integrating equation (14):

$$
E(V)=K \times C F_{0} \int_{0}^{t} e^{A d t} e^{-(\alpha-\partial) t} d t
$$

The final expression for the project expected value is obtained as follows,

$$
E V=\frac{K \times C F_{0}}{((\alpha-\partial)-A)}\left[1-e^{-((\alpha-\partial)-A) t}\right]
$$

Where 

$A$ : project cash flow growth trend
$\alpha$ : risk adjusted discount rate
$\partial$ : dividend yield.

To find the project growth variance, the variance formula is applied to the value of $d R$ defined in expression (8). That is : $\operatorname{Var}(d R)=E\left(d R^{2}\right)-(E|d R|)^{2}$; and from equation (12) is deduced that for any very small interval of time $d t$, $(E|d R|)^{2}=0$, and for instance $\operatorname{Var}(d R)=E\left(d R^{2}\right)$. The final formula for the variance of the project cash flow growth trend $\left(\sigma_{v}\right)$ will be the one expressed in equation (16). In fact, it is obtained a very similar volatility expression to the one deducted by Suslick and Costa(2006). Although the expression (16) represents an expected project return volatility, in this dissertation this expression is not used for calculating project return volatility, it is used monte Carlo simulation and other methods, such as the one proposed by Coopeland and Antikarov (2001) and Brandão, Hahn and Dyer (2012)

$$
\sigma_{v}^{2}=x_{c}^{2} \sigma_{c}^{2}+x_{m}^{2} \sigma_{m}^{2}+2 x_{c} x_{m} \sigma_{c} \sigma_{m} \rho
$$

To find the project expected value at any time $t$, a perpetual cash flow $(C F)$ is assumed using Monte Carlo simulations on equation (9). For this purpose, the initial cash flow $\left(C F_{0}\right)$ is determined, which will be the current cash flow and will increase according to the parameters found in equations (13) and (16).

The project value obtained in each period, including the initial value of the project without real options, is determined by discounting cash flows using the riskadjusted rate of the company (WACC), with a certain level of leverage. It will also be found the main project's parameters, such as project growth or return, volatility, skewness and kurtosis.

The project valuation considering the embedded options is done under a risk neutral approach, using the risk-free rate as the discount rate, as in Brandão and Dyer (2005a and 2005b). 
Since it is assumed that the project has a certain level of constant leverage, the project equity value, and particularly the stock value issued to finance the project can be calculated for any time $t$, according to the following expression:

$$
S_{t}=\frac{E V_{t}}{Q \times(1+\mathrm{L})}
$$

Where

St: Stock price at time t.

$Q$ : Number of common shares outstanding

$\mathcal{L}$ : constant leverage (Debt / Equity)

$E V_{t}$ : Expected value, including debt, of the project in the period $t$

The level of leverage $(\mathcal{L})$ is quite important because of its impact in project equity value. According to equation (17); the greater the level of leverage the lower the expected equity value, assuming constant production.

The variable St is the price or fundamental value of each common stock at time $t$, and this value could be seen as the strike price to consider if any embedded option, or combined options, in the project add value and should be exercised. These values are obtained from the project expected value $(E V)$ according to the Monte Carlo simulations performed before. The logic proposed by Baerle and Cakici (1998) is considered, since the adjusted expected stock values are the strike prices, and they will act as the underlying asset without options. In this dissertation, the project value at any time $t$ is represented by the project equity value, which means the price of issued stocks.

\subsection{1}

\section{Building a recombining binomial tree}

After obtaining project parameters, the model begins with the construction of a recombining standard binomial tree using constant volatility. The Copeland and Antikarov (2001) approach is used to construct a recombinant binomial tree that models the behavior of the project value. The proposed methodology uses constant 
volatility, which was found previously using Monte Carlo simulations. Like these authors, it is assumed that the project value (EV) follows an GBM.

One of the criticisms on the approach presented by Copeland and Antikarov (2001) is that by using the binomial tree of Cox, Ross and Rubinstein (1979), they attributes that all roads have the same probability. In this work, different path probabilities are defined by a weight function according to Jackweth (1994) approach, which will be explained in the following paragraphs. Figure 2 shows a standard recombining binomial tree.

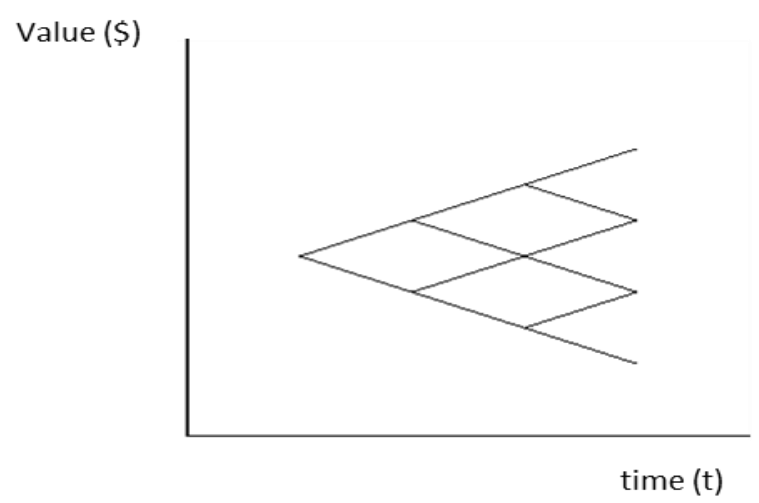

Figure 2 : A recombining binomial tree

Once the standard recombining binomial tree is built, the final nodal probabilities are found for each expected project value. In this work, a five period binomial tree is used.

The model proposes a different way to calculate the ending nodal probabilities. They are adjusted by other risk factors, such as project return skewness and kurtosis. Monte Carlo simulations are done to specify the probability distribution of project returns and its skewness and kurtosis values. To achieve this purpose, the model use the Gram - Charlier expansion to transform the binomial probability found in the already constructed recombining binomial tree. Since the probability distribution of project return is unimodal, the Gram- Charlier expansion is enough to adjust ending nodal probabilities as mentioned in Rubistein (1998). As a result, the probability distribution will not only consider the volatility of the project's returns, but also its skewness and kurtosis. 
As mentioned before, the Gram - Charlier expansion can be used to adjust a binomial risk neutral distribution, especially when the underlying asset cannot take negative values, as the case about expected project values. While a project's NPV can be negative; our analysis is focused on the expected project values (PV).

To have a better understanding of project value modelling, a simulated expected project value in year three is presented in figure 3. This is an expected project value obtained from our applied case, which will be explained with detail in the next chapter. As can be seen, project expected value is lognormaly distributed. It has a skewness of almost 1.8 and a kurtosis greater than 9 .

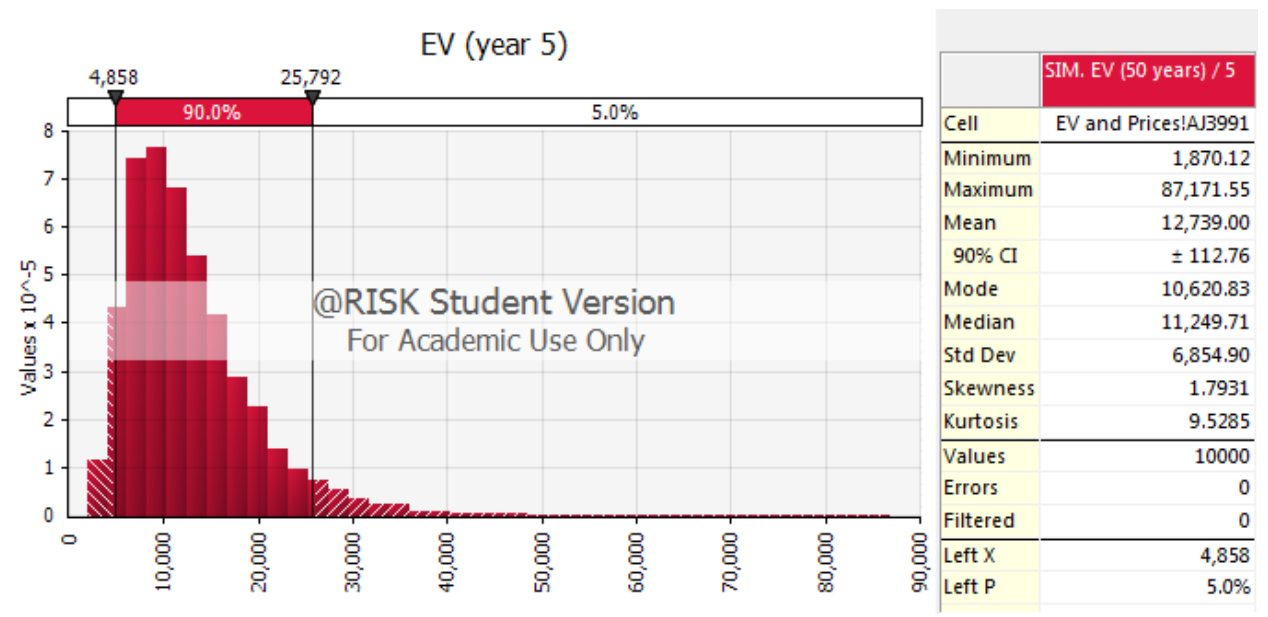

Figure 3: Project expected value

In figure 4, the annual simulated project return is also presented to understand its distribution. Although the project value follows a GBM, and it is log normally distributed, its return is not normally distributed. The annual project return presents a mean of almost $2.30 \%$ and a standard deviation of $10.38 \%$ approximately. It also has a skewness of 0.4 , different from zero; and a kurtosis greater than three. These parameters have been calculated applying Monte Carlo simulation to the growth percentage from time zero to year five, such as an annual compounding rate of return for five years according to the Coopeland and Antikarov (2001) approach. 


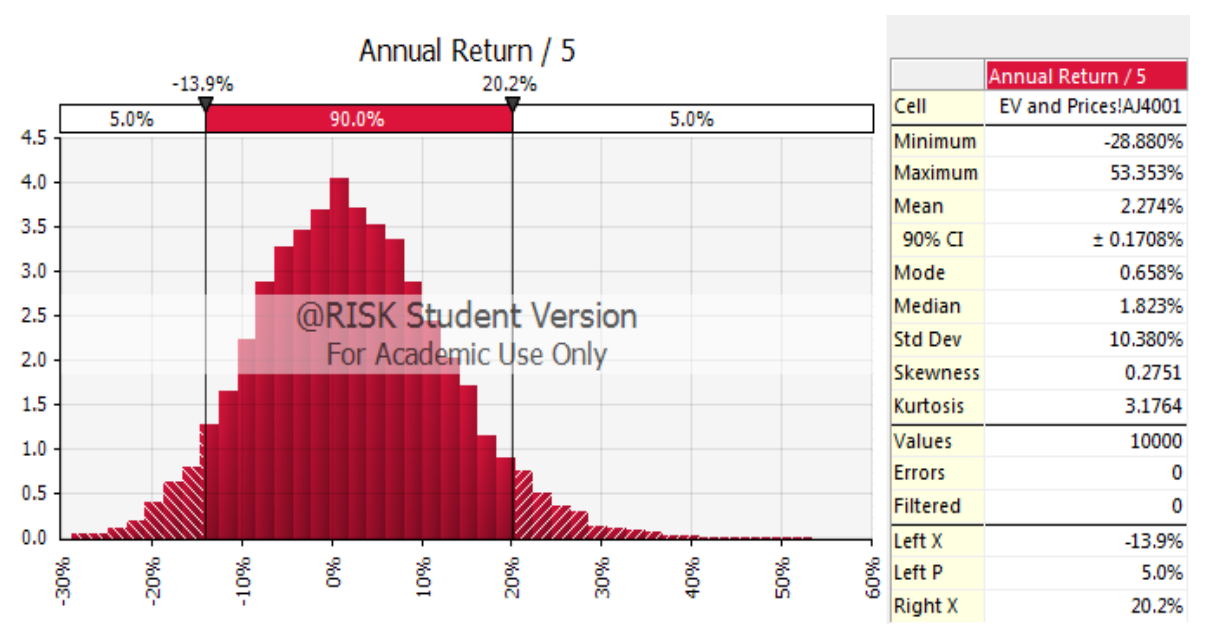

Figure 4 : Project return parameters using CA method

In figure 5, the same project parameters are shown using Brandão, Dyer and Hahn and Dyer (2012) method. The annual average project return is $10.3 \%$ and it has a volatility of $5.11 \%$. Although in this case, the found volatility is lower than the previous case, the values of skewness and kurtosis are greater, which means that lower project returns are more probable. For the purpose of this dissertation, an average volatility between both methods, around 7\%, will be used in order to construct the implied binomial tree. This process only will be done in the implied recombining binomial tree.

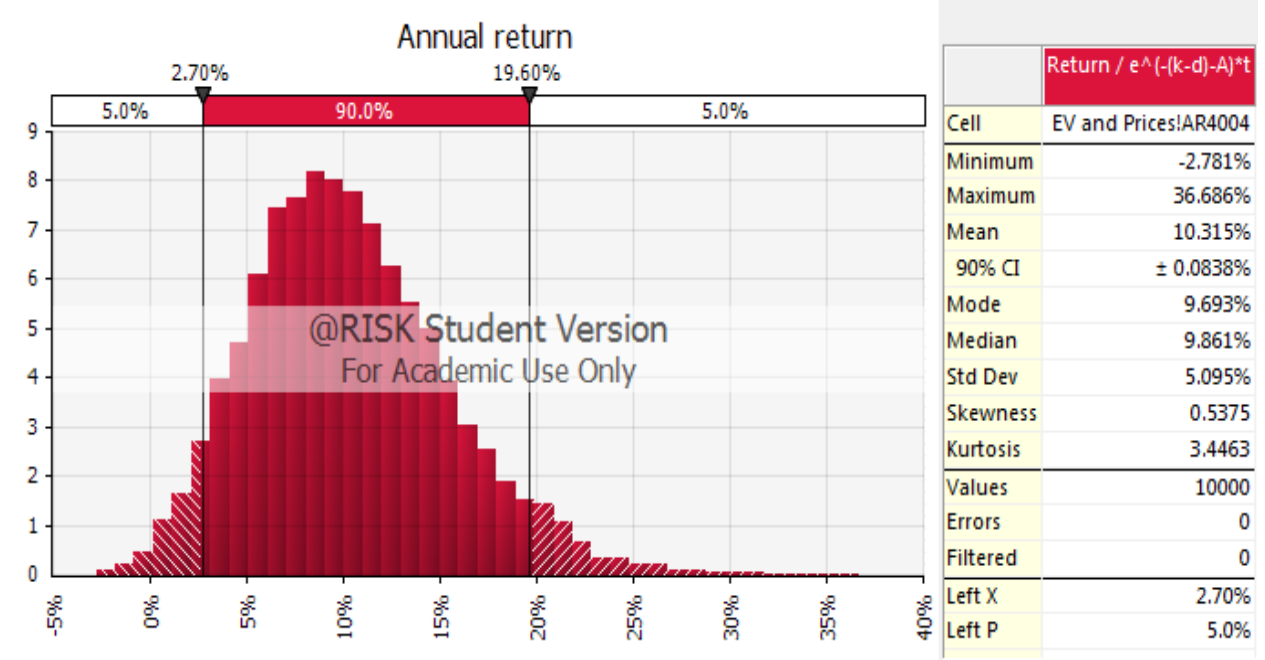

Figure 5 : Project return parameters using $\mathrm{BDH}$ method

In order to consider project return skewness and kurtosis, which are indicators of risk as mentioned lines above, this model proposes adjusting the final nodal 
probabilities in the standard binomial tree using the Gram - Charlier expansion. The binomial risk neutral probability $\mathrm{b}(\mathrm{x})$ can be adjusted using equations (18) and (19):

$$
\begin{aligned}
& f(x)=g c(x) \times b(x) \\
& g c(x)=1+\frac{1}{6} \xi\left(x^{3}-3 x\right)+\frac{1}{24}(\kappa-3)\left(x^{4}-6 x^{2}+3\right)
\end{aligned}
$$

Where,

$f(x)$ : is the adjusted probability distribution

$b(x)$ : is the binomial risk neutral probability distribution

$g c(x)$ : is the Gram - Charlier expansion factor.

$\xi:$ Asymmetry level of cash flow growth rates

$\kappa:$ Kurtosis of cash flow growth rates

This approach will be useful when the project value can be explained by a lognormal distribution, which implies a normal distribution for project returns. However, as mentioned before, not always project return can be totally explained by a normal distribution, even if we assume project values follow a GBM as mentioned before. It is well known that if a variable is normally distributed, it presents zero skewness and its kurtosis is equal to three. This dissertation proposes a methodology to assess project risk when project return shows a non-zero skewness and a greater than three kurtosis. In fact, if the project presents a positive skewness, the probability for a lower expected value is greater than for a higher expected value.

Unfortunately, the adjusted probability distribution is an approximation. Generally the sum of probabilities in all the nodes is different from one. To correct this problem, the new each node probability is recalculated assuming that the current total sum of the adjusted probabilities is the new total value. Then each new nodal adjusted probability is divided by the new total sum of the adjusted probabilities. This process is done for each node. 
After obtaining the initial binomial tree based on constant volatility and adjusted by skewness and kurtosis, a general implied binomial tree is built, which will allow the calculation of the present value of the project.

There is more than one path to follow to obtain each project final ending value. The paths could also have different probabilities as in the general binomial tree of Jackwerth (1997). We will use the general binomial tree developed by Jackwerth (1994) and arbitrarily assign a weight to each path.

This allocation allows the analyst to use the criteria to define what would be the most likely path, which actually means which followed path would have greater weight $(w)$. This weight will represent the analyst decision, which could be based on market information processed by the analyst. A number of features to optimize and find the best distribution or weight assigned to each path were developed by Lim and Zhi (2002).

In this dissertation, a weight $(w)$ is assigned to obtain a concave weight function because according to studies developed by Jackwerth (1994), Lim and Zhi (2002) and Wang and Dyer (2010) concave functions generate a more likely scenario in the sense that it is more reliable to think that an asset could first go down and then climb rather than going up and decline later.

The concave function that is used to determine the general implied tree will be the linear function developed by Lim and Zhi (2002), which is shown in equation (20).

$$
w(x)= \begin{cases}\frac{x a}{0.5} & \text { for } x \in[0,0.5] \\ \frac{(1-\alpha)(x-0.5)}{0,5} & \text { for } x \in[0.5,1]\end{cases}
$$

The value of $\alpha$ will determine the weights for each path, and values greater than 0.5 allows that upper paths be more probable. This value incorporates the 
analyst criteria based on information processed. In this model a value of $\alpha$ equal to 0.75 is assumed, considering that upper values for project are more probable. In their research, Wang and Dyer (2010) perform an optimization function to determine the value of $\alpha$ in order to find the best match between simulated option values and market prices of traded options. In this case, it is not necessary, by taking an $\alpha=0.75$ it is explicitly incorporating the analyst criteria, since the values of the upper nodes, regardless of the probabilities found before, have a greater weight. The reasoning behind this is that one would like to choose a path looping down first and then coming up, than a path looping up and then coming down, as stated by Lim and Zhi (2002). For instance, when the value of $\alpha$ is 0.75 , the concave weight function tends to give more probable values to the upper nodes, which may incorporate the analyst criteria for the reasons explained above.

The value of the asset will be obtained through transition probabilities defined according to new nodal probabilities obtained as follows:

$$
p_{t-1, j}=w\left(\frac{j+1}{t}\right) p_{t, j+1}+\left(1-w\left(\frac{j}{t}\right)\right) p_{t, j}
$$

The transition probabilities are defined:

$$
q_{t-1, j}=\frac{w\left(\frac{j+1}{t}\right) p_{t, j+1}}{p_{t-1, j}}
$$

And the stock value $(\mathrm{S})$ in the preceding node is determined by equation (23):

$$
s_{t-1, j}=\frac{q_{t-1, j} s_{t, j+1}+\left(1-q_{t-1, j}\right) s_{t, j}}{e^{r t}}
$$

In this way the value of the company according to the transition probabilities is expressed. There is not the possibility of arbitration since these probabilities vary between zero and one.

Finally, all the possible managerial flexibility can be considered trough the project life along the tree. The value of the project could be found incorporating 
real options the company may have, it would suffice to add impact in the per considered the decision would be implemented.

\section{4 .2}

\section{Building a non- recombining binomial tree}

A different approach to value the same project can be done using changing volatility. When using non-constant volatility a non-recombining binomial tree is built, and this analysis situation is quite more interesting and even more realistic than the one presented before. Projects or companies have many variables that affect project future values. These variables could change during project life time, which usually happens and makes more difficult to assess real projects. In this approach, a changing volatility based on market prices allows to incorporate a different uncertainty during project life time. Figure 6 shows a project behavior considering changing volatility in a binomial tree.

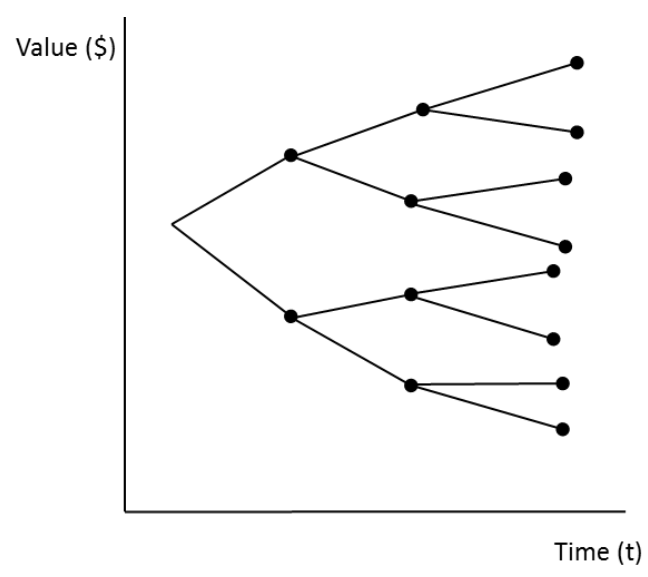

Figure 6 : non-recombining binomial tree (NRBT)

Projects do not have the same risk during their life time, in fact capital structure can change which could make investor's risk perception change as well. This work present a risk analysis by taking in consideration the skewness and kurtorsis of project returns in each period of time, which is each binomial period.

A forward binomial tree is built considering the expected enterprises values for each period, and taking account the respective volatility for each period, the 
expected values are calculated using Monte Carlo simulations, as mentioned before. In this manner, the simulations would provide certain level of volatility, average growth, skewness and kurtosis for each period. Once again, it is assumed that the project value follows a GBM.

To find the expected value of the project for each period, an eternal cash flow is simulated in five consecutive periods. Moreover, an initial cash flow ( $\mathrm{CFo}$ ) is determined and it will increase according to the parameters found in equations (13) and (16).

As in the recombining implied tree approach, the values obtained in each period, including the initial value of the project without options, are determined by discounting cash flows using the risk-adjusted rate of the company (WACC), with constant level of leverage in each period. The project valuation considering its real options is done under a neutral risk approach, using the risk-free rate as the discount rate, as in Brandão and Dyer (2005a and 2005b). The expected value of the company is obtained using the equation (15). In this approach, the level of constant leverage is also considered and the project equity value will be calculated according to the equation (17).

As mentioned before, the variable St is the price or fundamental value of each common stock at time $t$ without options. The difference in this approach is that these values can be calculated using non constant volatility, and they will be the expected values obtained from the Monte Carlo simulations done for each period. The initial project value is the same as in the recombining implied tree.

The logic proposed by Baerle and Cakici (1998) is considered, since the adjusted expected stock values are the strike prices, and they will act as the underlying asset without options. This is done to increase the stability of implied binomial trees in order to find nodal and path probabilities. In this manner it is possible to find the project value with options in any period with less arbitrage violations. In this dissertation the project value with options is only calculated in time zero. 
As mentioned before, Figure 7 shows the behavior of the project value considering a different volatility for each period, and more important, a different probability for each path. In fact there is just one path to reach each project value in each node.

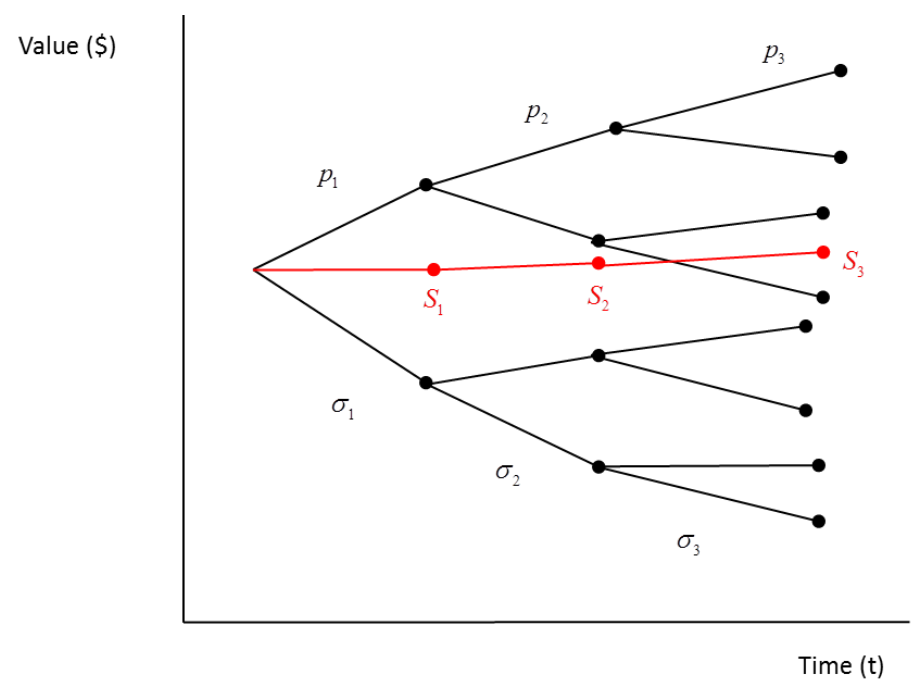

Figure 7 : Simulated project expected value

Using the different volatilities per period, the risk neutral probabilities per period is found according to equation (24):

$$
p_{t}=\frac{e^{r t}-d_{t}}{u_{t}-d_{t}}
$$

where $u_{t}=e^{\sigma_{t}}$ and $d_{t}=e^{-\sigma_{t}}$

Once again, the level of skewness and kurtosis of the future expected values are taken into consideration to analyze the risk in the project for each period of analysis. If the project presents a positive skewness for each period, the probability for lower expected values is greater than for higher expected values. The level of uncertainty would be different in each time interval.

The model developed in this dissertation proposes to specify the probability distribution of the underlying asset (project) using determined values for skewness and kurtosis for each period, so the probability distribution would be different in 
each period. As a result, the analysis will not only consider the project return volatility, but also its respective skewness and kurtosis at any time t.

To achieve this purpose, the model use the Gram - Charlier expansion to transform the binomial probability found in the already constructed non recombining binomial tree for each period of time.

As mentioned in Rubinstein (1998), the Gram - Charlier expansion can be used to adjust a binomial risk neutral distribution especially when the underlying asset won't have negative values, as the expected project values. As already know, assets do not have negative values. Projects NPV could be negative, however the analysis is focused on expected project values. The binomial risk neutral probability $b(x)$ can be adjusted the expressions (18) and (19) for each year.

Using the Gram - Charlier expansion, each nodal probability is adjusted for each year. As mentioned before in the construction on the recombining binomial tree, the total sum of the nodal probabilities in each period is not one. For instance the same adjustment is done, and the new nodal probabilities are found as in the way described for the recombining binomial tree mentioned before.

There is just one path to obtain each project final ending value. The paths only will have one probability to reach this value. As a result, the general implied binomial tree of Jackwerth (1997) cannot be constructed because there is no way to assign any weight function to each path as done in Lim and Zhi (2002). However, in order to keep the analyst criteria in the construction of the implied binomial tree, the same weigh function defined by expression (20) could be applied for each node. In this case, since there are only two paths that depart from each node, the path that goes up will be assigned always with the maximum weight, no matter what value of alfa we assigned. In other words, the upper path will be assigned with a hundred percent of weight.

Finally, all the possible managerial flexibility can be considered trough the project life along the tree. The value of the project could be found incorporating options the company may have, such as delay or expand for example. It would be enough to add impact of any flexibility in each period of analysis. The project return 
follows a similar distribution each year, but they have a different risk in each period. The project return volatility is the standard deviation of the expected project return from one year to previous one. These volatilities are calculated using Monte Carlo simulation. This process is done from year one to year five, so there are five different volatilities, one from each year. When considering a changing volatility during the project life, the embedded options may have a greater impact than when analyzing the project with constant volatility. In the application chapter, the found parameters are shown in table 9. 


\section{4.}

\section{Application}

The model will be applied to a mining project, and it will be considered two mineral as sources of revenues, copper and molybdenum. It will be supposed that one of the two minerals will have a major participation in the project income, as it happens in most of the mining projects. In this particular case, copper will represent 95\% of project sales. The use of the proposed model will be illustrated considering two methodologies proposed in this dissertation: using recombining trees and nonrecombining trees. For comparison purposes, the same analysis is done in a standard recombining binomial proposed for CRR (1979). The last three year daily prices in American dollar per metric ton for the two minerals are presented in figure 8. An Augmented Dickey Fuller test was done with copper prices in order to validate that follows a GBM. The t statistic value found was -1.22 , which is greater than -2.86 ; the critical value for a $95 \%$ confidence level. For instance it is not possible to reject the null hypothesis and there is a unit root and the time series for copper price is not stationary.

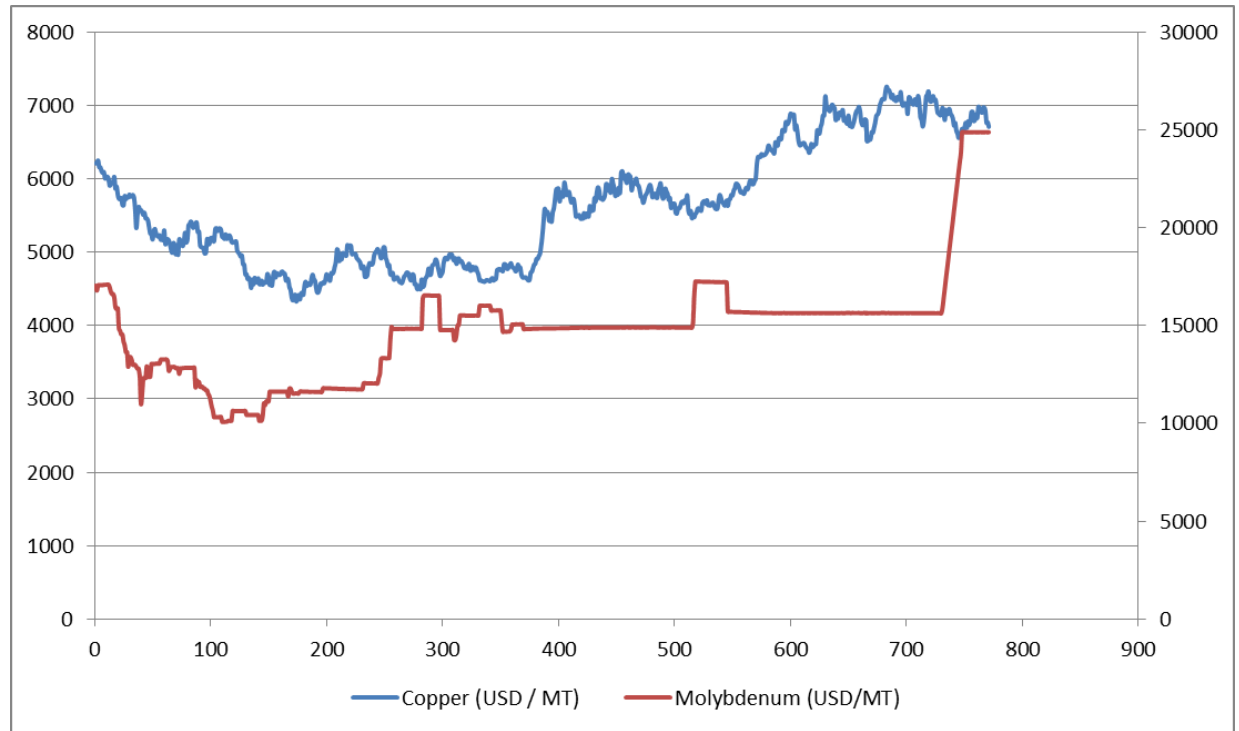

Figure 8: Historical daily prices of minerals

It will also be considered that the project can be listed in a stock market, as stated in Miranda, Brandão, and Lazo (2017) to fund the project with a certain level 
of debt. The parameters that will consider for the applied case are shown in Table 1

Table 1: List of variables

\begin{tabular}{|l|l|}
\hline$x_{c}$ & percentage of sales corresponding to copper \\
\hline$x_{m}$ & percentage of sales corresponding to molybdenum. \\
\hline$u_{c}$ & copper annual yield. \\
\hline$u_{m}$ & molybdenum annual yield. \\
\hline$\sigma_{c}$ & copper yield volatility. \\
\hline$\sigma_{m}$ & annual molybdenum yield volatility. \\
\hline$\rho$ & correlation between copper and molybdenum yields. \\
\hline$\alpha$ & cost of capital (wacc) \\
\hline$\delta$ & dividend yield \\
\hline$y_{c}$ & copper convenience yield. \\
\hline$y_{m}$ & molybdenum convenience yield. \\
\hline$F C_{0}$ & current free cash flow. \\
\hline$t$ & evaluation time \\
\hline$r_{f}$ & risk free rate \\
\hline
\end{tabular}

As discussed previously, the initial value of the project without options is obtained considering an eternal free cash flow $(F C F)$ according to equation (9) and using Monte Carlo simulations. The initial FCF is assumed on USD 2,500.00 MM as shown in Annex 1. The selected minerals are Copper and Molybdenum

The parameter values for the two minerals are determined from the historical daily prices from almost three years, specifically from May 2015; which are show in figure 7. The parameters are listed below:

$$
\begin{aligned}
& x_{c}=95 \% x_{m}=5 \% \quad u_{c}=3.6 \%, u_{m}=17.67 \% ; \sigma_{c}=23.70 \%, \sigma_{m}=25.68 \%, \\
& \rho_{c m}=-0.02, \alpha=9.3 \%, t=50 \text { years } \partial=0.5 \%, y_{c}=0.02 \%, y_{m}=0.01 \%, \\
& F C_{0}=2,500, r_{f}=5 \%
\end{aligned}
$$

The lifetime period of the project will be considered large enough, 50 years, so it can be considered as a perpetual cash flow. The risk free rate assumed is $5 \%$. 
It will also be assumed a constant percentage of sales for both metals. This is something that certainly can be variable; however it has been observed that in several mining projects, the ratio of sales for each mineral remains almost constant year to year.

As mentioned before, the price of copper and molybdenum follow a GBM, and based on this assumption the EV of the project is calculated. The number $(Q)$ of common stock used is 785 million and the debt ratio $(L)$ used is 0.23 . In table 2 we show the initial project value without options and the value of each stock that could be issued to finance part of the project.

Table 2: Initial project value without options

\begin{tabular}{lc}
\multicolumn{1}{c}{ Year } & $\mathbf{0}$ \\
\hline Exp. EV (USD millions) & $\$ 10,278.24$ \\
Debt/Equity & 0.23 \\
Equity Value & $\$ 7,947.13$ \\
Shares (in millions) & 785.00 \\
\cline { 2 - 2 } Stock price & $\mathbf{\$ 1 0 . 1 2}$
\end{tabular}

The project expected value is approximately USD 10,280 MM, and since it is considered a debt to equity ratio of 0.23 , the project equity value turns out to be USD 7,947.13.92 MM, which divided by 785 million shares, gives a stock price of USD 10.12. This will be the initial project value without options. As mentioned before, the project value will be modeled through its equity value for each year. As an example, Figure 9 shows the Monte Carlo simulations results for the project equity expected value in year five, which is almost USD 13,000 MM and considering that there were will not be used more shares, the expected stock price in year five will be USD 11.84 


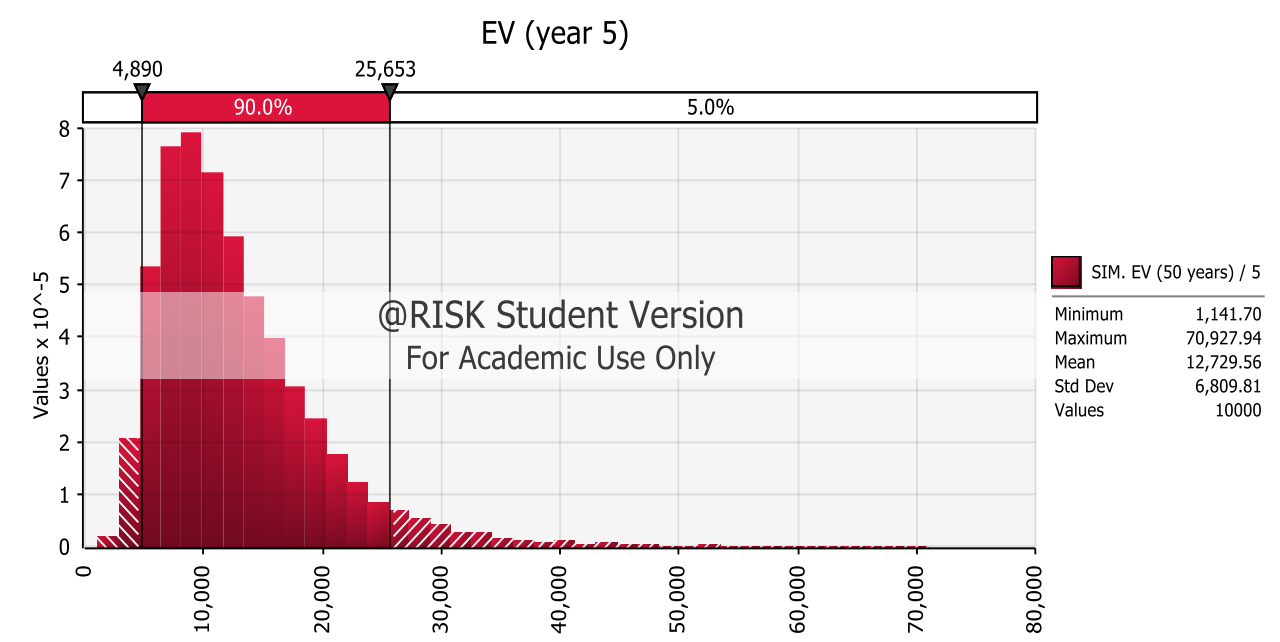

Figure 9 :Project expected value in year five without options

\section{1}

\section{Applied model to a recombining binomial tree (RBT)}

Firstly, the project return parameters, such as volatility, skewness and kurtosis, are found to construct the recombining standard binomial tree. This is done using the logic and methodology described in the previous section. Figure 10 shows the found results using Monte Carlo simulations using the BDH (2010) approach.

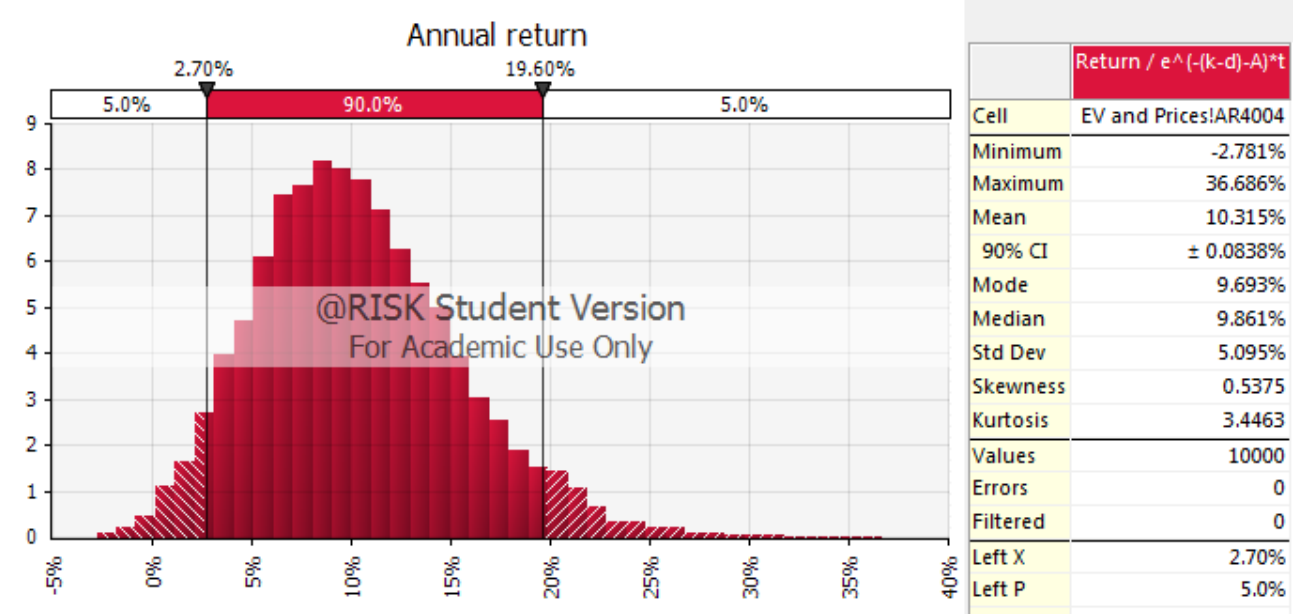

Figure 10 : Project return parameters in a RBT

The average annual project return is $10.315 \%$ and its volatility is almost $5 \%$. This volatility will be assumed to be constant through the life of the project and will be used to construct the initial recombining binomial tree according to CRR (1979). 
The risk neutral probability along the tree is $0.84(p)$, which is obtained from equation (24). Figure 11 shows the initial binomial tree.

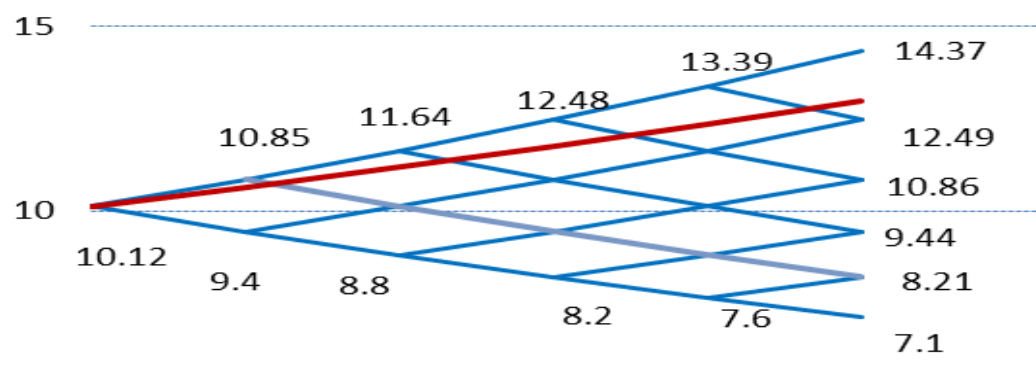

5

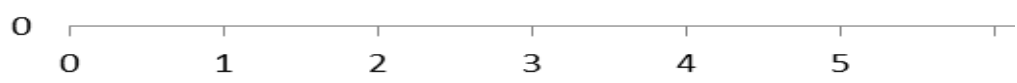

Figure 11 : Initial recombining binomial tree

Table 3 shows the project value in each node of the binomial tree and its respective nodal probability.

Table 3 : Recombining binomial tree - Initial nodal probabilities

\begin{tabular}{ccccccc} 
nodal probabilities & $\mathbf{0}$ & $\mathbf{1}$ & $\mathbf{2}$ & $\mathbf{3}$ & $\mathbf{4}$ & $\mathbf{5}$ \\
\hline & $100 \%$ & $84.84 \%$ & $71.98 \%$ & $61.07 \%$ & $51.82 \%$ & $43.96 \%$ \\
& & $15.16 \%$ & $25.72 \%$ & $32.73 \%$ & $37.03 \%$ & $39.27 \%$ \\
& & $2.30 \%$ & $5.85 \%$ & $9.92 \%$ & $14.03 \%$ \\
& & & $0.35 \%$ & $1.18 \%$ & $2.51 \%$ \\
& & & & $0.05 \%$ & $0.22 \%$ \\
& & & & & & $0.01 \%$
\end{tabular}

As mentioned in the methodology description, the final probabilities for each node should be adjusted for this level of skewness and kurtosis using the GramCharlier expansion factor using equations (18) and (19). Because of this adjustment, the final nodal probabilities will be $42.94 \%, 38.96 \%, 15.07 \%$ and $2.78 \%, 0.25 \%$ and $0.01 \%$ as shown in table 4. 
Table 4 : Adjusted nodal probabilities by Skewness and kurtosis

\begin{tabular}{ccccccc} 
Adj. Probabilities & 0 & 1 & 2 & 3 & 4 & 5 \\
\hline & $100.00 \%$ & $66.70 \%$ & $57.70 \%$ & $51.59 \%$ & $46.84 \%$ & $42.94 \%$ \\
& & $33.30 \%$ & $36.02 \%$ & $36.61 \%$ & $38.07 \%$ & $38.96 \%$ \\
& & $6.29 \%$ & $11.02 \%$ & $13.16 \%$ & $15.07 \%$ \\
& & & & $0.77 \%$ & $1.84 \%$ & $2.78 \%$ \\
& & & & & $0.08 \%$ & $0.25 \%$ \\
& & & & & & $0.01 \%$
\end{tabular}

Once the final nodal probabilities are adjusted, the general implied binomial tree is constructed to find previous nodal probabilities, following a Jacckwerth (1994) approach. For this implied tree a weight concave function defined in Lim and Zhi (2002) with an alpha equal to 0.75 is used. Table 4 shows the results obtained for all nodal probabilities. It is very important to notice that the initial project value is almost not altered; only the nodal probabilities are different. However, this will impact in the initial value when managerial flexibility (options) is considered along the tree. Table 5 shows the simulated project value without options considering the probability adjustments described lines above.

Table 5 : Simulated project value with adjustments

\begin{tabular}{lcccccc}
$\begin{array}{l}\text { Simulated } \\
\text { project value }\end{array}$ & $\mathbf{0}$ & $\mathbf{1}$ & $\mathbf{2}$ & $\mathbf{3}$ & $\mathbf{4}$ & $\mathbf{5}$ \\
\hline 10.09 & 11.13 & 11.92 & 12.70 & 13.52 & 14.37 \\
& 9.56 & 10.30 & 11.05 & 11.76 & 12.49 \\
& & 8.97 & 9.58 & 10.21 & 10.86 \\
& & & 8.31 & 8.87 & 9.44 \\
& & & & 7.70 & 8.21 \\
& & & & & & 7.13
\end{tabular}

To show the impact of managerial flexibility on project value, two options are considered during project life: selling the project participation at the end of any year and expand the project at the end of year five.

The project can be sold by USD 7,000.00 million, which turns to be USD 8.92 each stock. The option to expand will increase value in 50\% but an investment of USD 3,000.00 million must be done. In this case, the stock price will depend on 
each nodal value. The following table presents the project value taking in consideration only the option to expand at the end of year five.

Table 6 : Project values with option to expand

\begin{tabular}{ccccccc} 
Project value & $\mathbf{0}$ & $\mathbf{1}$ & $\mathbf{2}$ & $\mathbf{3}$ & $\mathbf{4}$ & $\mathbf{5}$ \\
\hline \multirow{2}{*}{12.16} & 13.56 & 14.59 & 15.60 & 16.64 & 17.73 \\
& 11.21 & 12.16 & 13.12 & 14.00 & 14.91 \\
& & 10.16 & 10.92 & 11.69 & 12.47 \\
& & & 9.02 & 9.67 & 10.34 \\
& & & & 7.94 & 8.49 \\
& & & & & 7.13
\end{tabular}

As shown in table 6 , the current project equity value is $20 \%$ more with the option to expand. When the project only consider the option to abandon, the value increase to USD 10.17 , only $0.7 \%$ more than the project without options, as can be seen in table 7. This little increase is because of the low sell price with the abandon option.

Table 7 : Project values with option to abandon

\begin{tabular}{ccccccc} 
Project value & $\mathbf{0}$ & $\mathbf{1}$ & $\mathbf{2}$ & $\mathbf{3}$ & $\mathbf{4}$ & $\mathbf{5}$ \\
\hline \multirow{2}{*}{10.17} & 11.16 & 11.93 & 12.71 & 13.52 & 14.37 \\
& 9.76 & 10.45 & 11.14 & 11.81 & 12.49 \\
& & 9.46 & 10.09 & 10.78 & 11.49 \\
& & & 8.92 & 9.11 & 9.65 \\
& & & & & 8.92
\end{tabular}

Finally, when both options are included, the project increases its value by $21.11 \%$, to USD 12.22, as shown in table 8. As noticed before, the option to abandon does not contributes significantly to increase project value. It is important to note that when the option to abandon is exercised the project will not continue and for instance some future nodes will not present any value, such as the ones shown in the lower nodes in year two and four in table 7 and 8. 
Table 8 : Project value with options to abandon and expand

\begin{tabular}{|c|c|c|c|c|c|c|}
\hline Project value & 0 & 1 & 2 & 3 & 4 & 5 \\
\hline & 12.15 & 13.56 & 14.59 & 15.60 & 16.64 & 17.73 \\
\hline & & 11.19 & 12.15 & 13.12 & 14.00 & 14.91 \\
\hline & & & 10.09 & 10.84 & 11.69 & 12.47 \\
\hline & & & & 8.92 & 8.92 & 10.34 \\
\hline
\end{tabular}

\section{2}

Applied model to a non -recombining binomial tree (NRBT)

The project return parameters for each year are found using Monte Carlo simulations. It is also considered an eternal cash flow for each year. These parameters will be used to construct the non-recombining binomial tree using the logic and methodology described in previous sections. Table 9 shows the project return parameters for each year.

Table 9 : Project parameters for each year

\begin{tabular}{lccccc}
\multicolumn{1}{c}{ Parameter } & Year 1 & Year 2 & Year 3 & Year 4 & Year 5 \\
\hline Expected return & $6.23 \%$ & $7.24 \%$ & $4.81 \%$ & $4.67 \%$ & $4.86 \%$ \\
Volatility & $29.23 \%$ & $29.37 \%$ & $28.74 \%$ & $28.78 \%$ & $29.06 \%$ \\
Skewness & 0.7851 & 0.8454 & 0.8134 & 0.8329 & 0.8085 \\
Kurtosis & 4.4114 & 4.2223 & 4.1681 & 4.0603 & 4.07 \\
Upisde probability (p) & $51.39 \%$ & $51.31 \%$ & $51.66 \%$ & $51.64 \%$ & $51.48 \%$
\end{tabular}

In figure 12, a simulation of the project return parameters are shown for year five. It can be seen that at this year the project presents certain level of positive skewness, and kurtosis value greater than three. 


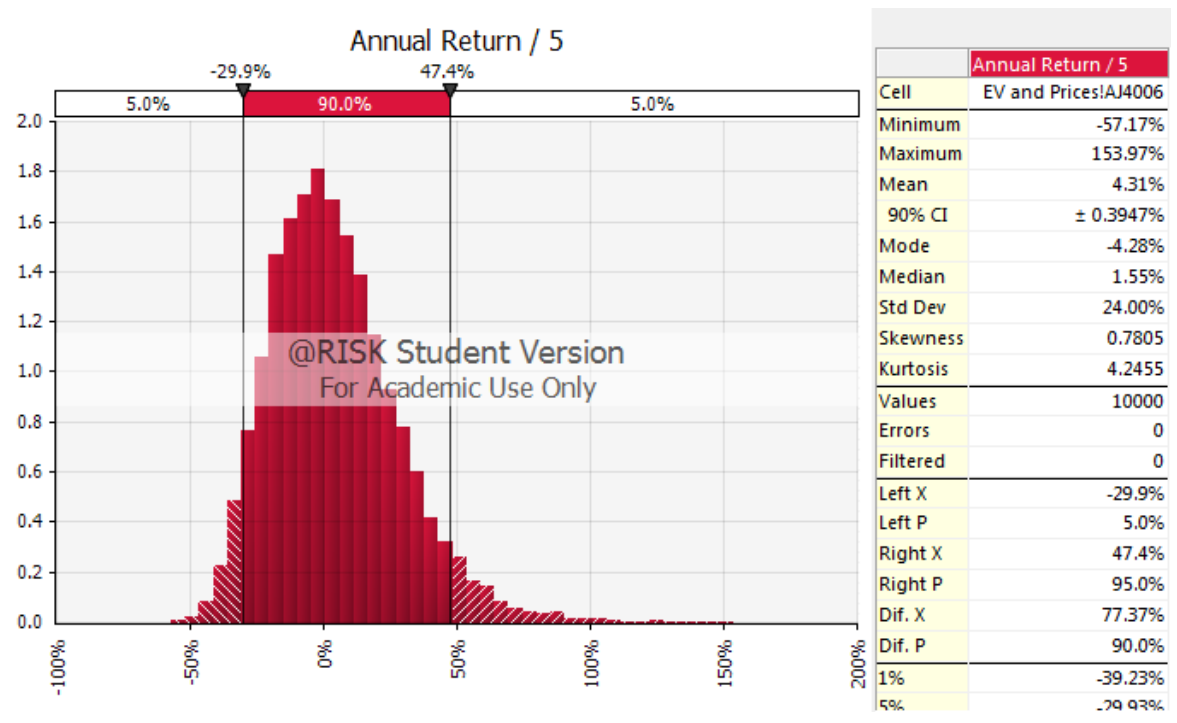

Figure 12 : Project return parameters in a NRBT

The initial non recombining binomial tree is constructed, and the expected project values without options are calculated, according to it's respectively volatility for each year. The results are shown in Figure 13.. 


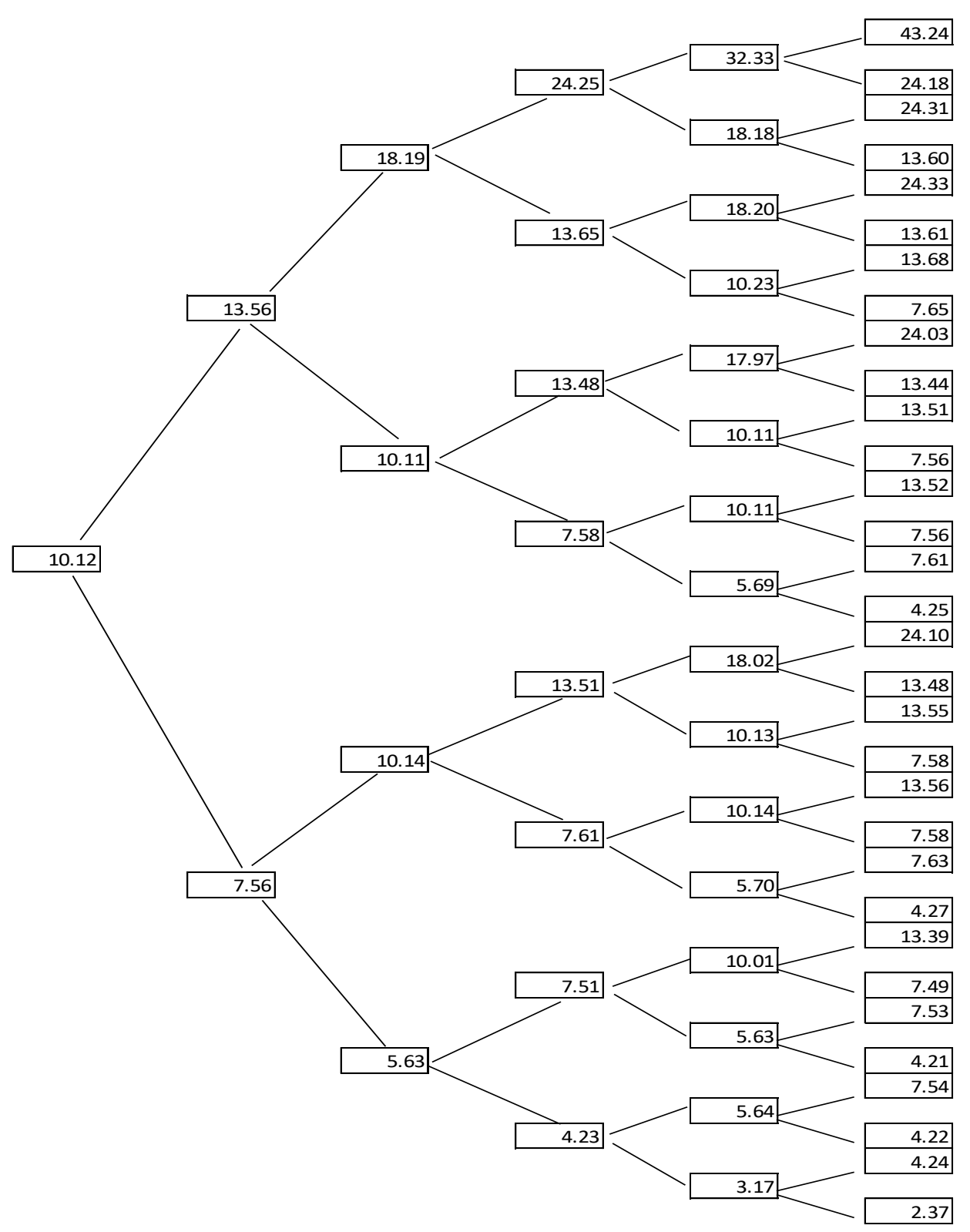

Figure 13 - Project value without options

As the project value is calculated for each node, the nodal probabilities are also obtained. These values are calculated by multiplying the upside and downside path probabilities to reach each node. The initial upside path probabilities for each year are shown table 9. For example, the upper ending node in year five is calculated as follows: $51.39 \% \times 51.31 \% \times 51.66 \% \times 51.64 \% \times 51.48 \%=3.62 \%$. Figure 14 shows all each nodal probabilities for each year. 


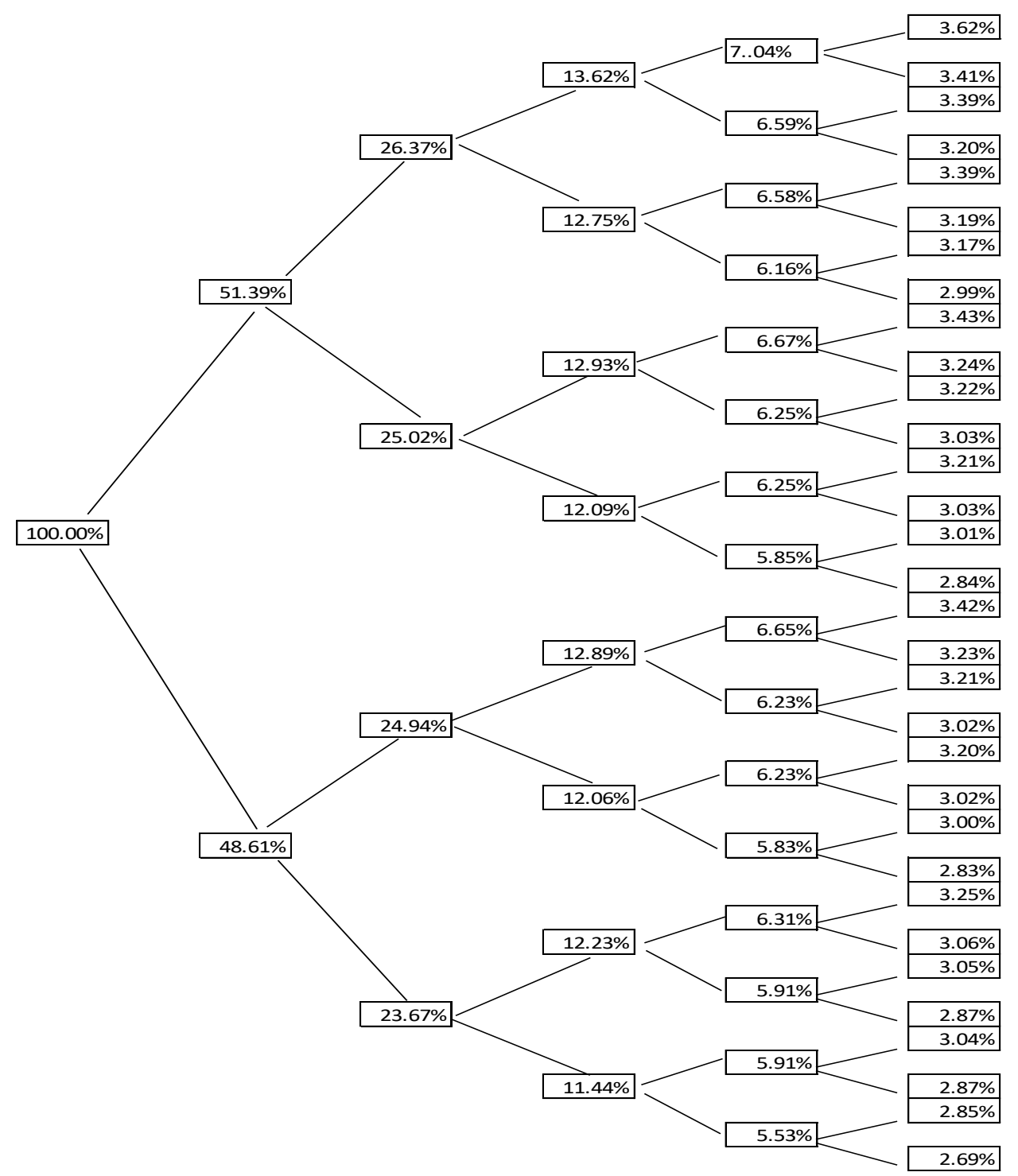

Figure 14 - NRBT - initial nodal probabilities

According to the values found in Figure 13 and 14, each project equity value is calculated. For example, the project equity value could be $\$ 43.24$ with a probability of $3.62 \%$ as the best case, in year five. However, the project return in year five has a positive skewness of 0.8 and a Kurtosis of 4.1, which implies that lower project values has more chance to occur than higher project values. The same approach is applied to analyze project equity value according to its respective skewness and kurtosis values in each year, as shown in table 9. .

Following the proposed model in this dissertation, each nodal probability will be adjusted using the Gran-Charlier expansion. As explained before, this factor 
adjustment is suitable for the applied case, because it's return distribution probability is unimodal.

The adjusted nodal probabilities for each year will be found multiplying the current nodal probabilities for the factor determined by equation 25 and 26. It is important to mention that each node in any year will be adjusted by its own adjustment factor. Figure 15 shows the final adjusted nodal probabilities. As can be observed, the lower nodes have more probability value than the ones previously seen in Figure 14. The difference in not so high, because the level of skewness is low for the applied case.

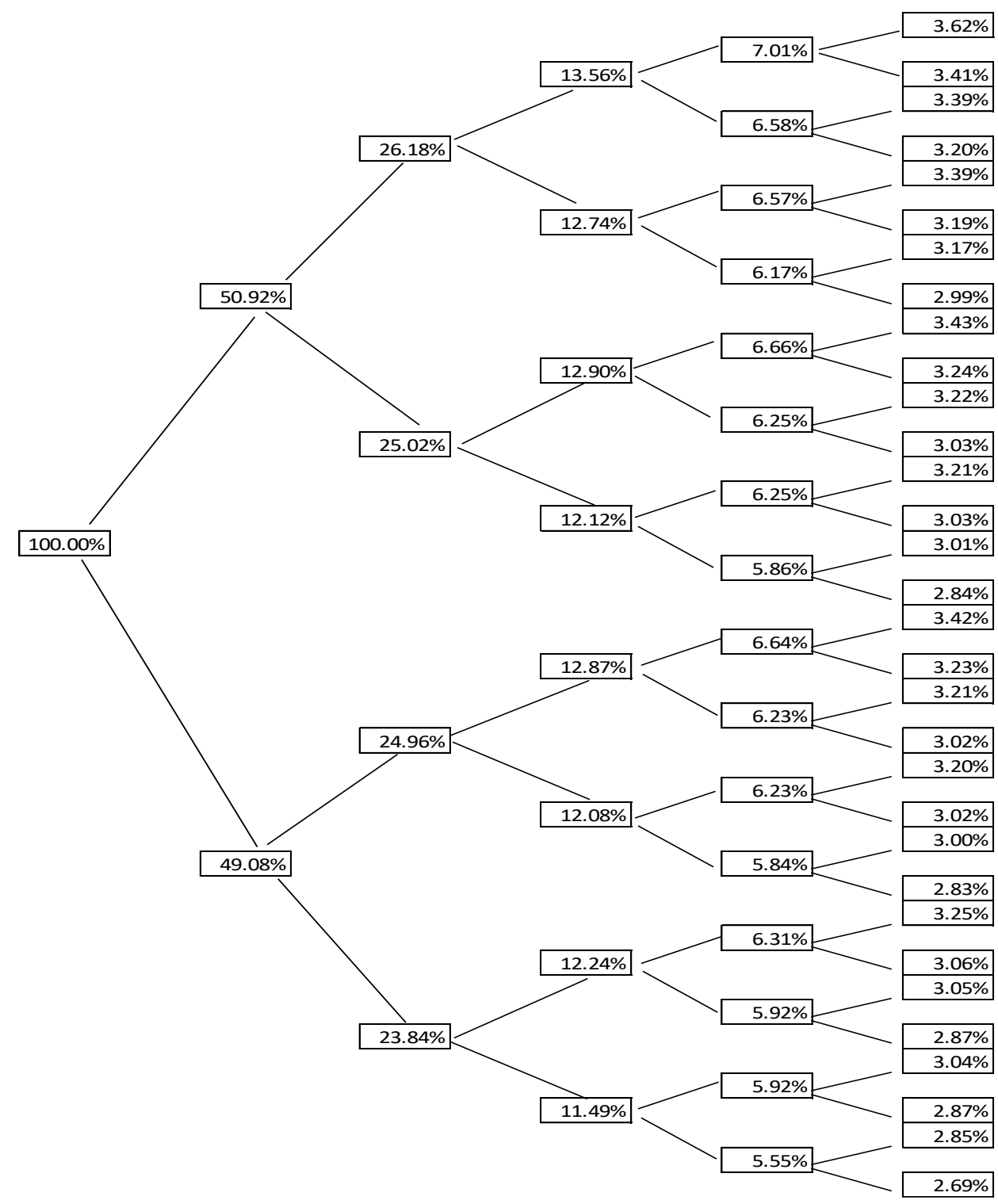

Figure 15 - Adjusted nodal probabilities 
The path probabilities for each node changes, which means they will not be the same upside probabilities for each year. For example in year 2, there are two upside path probabilities, $51.42 \%$ and $50.85 \%$ to reach the upper and third node respectively. Figure 16 presents the new path probabibilites.

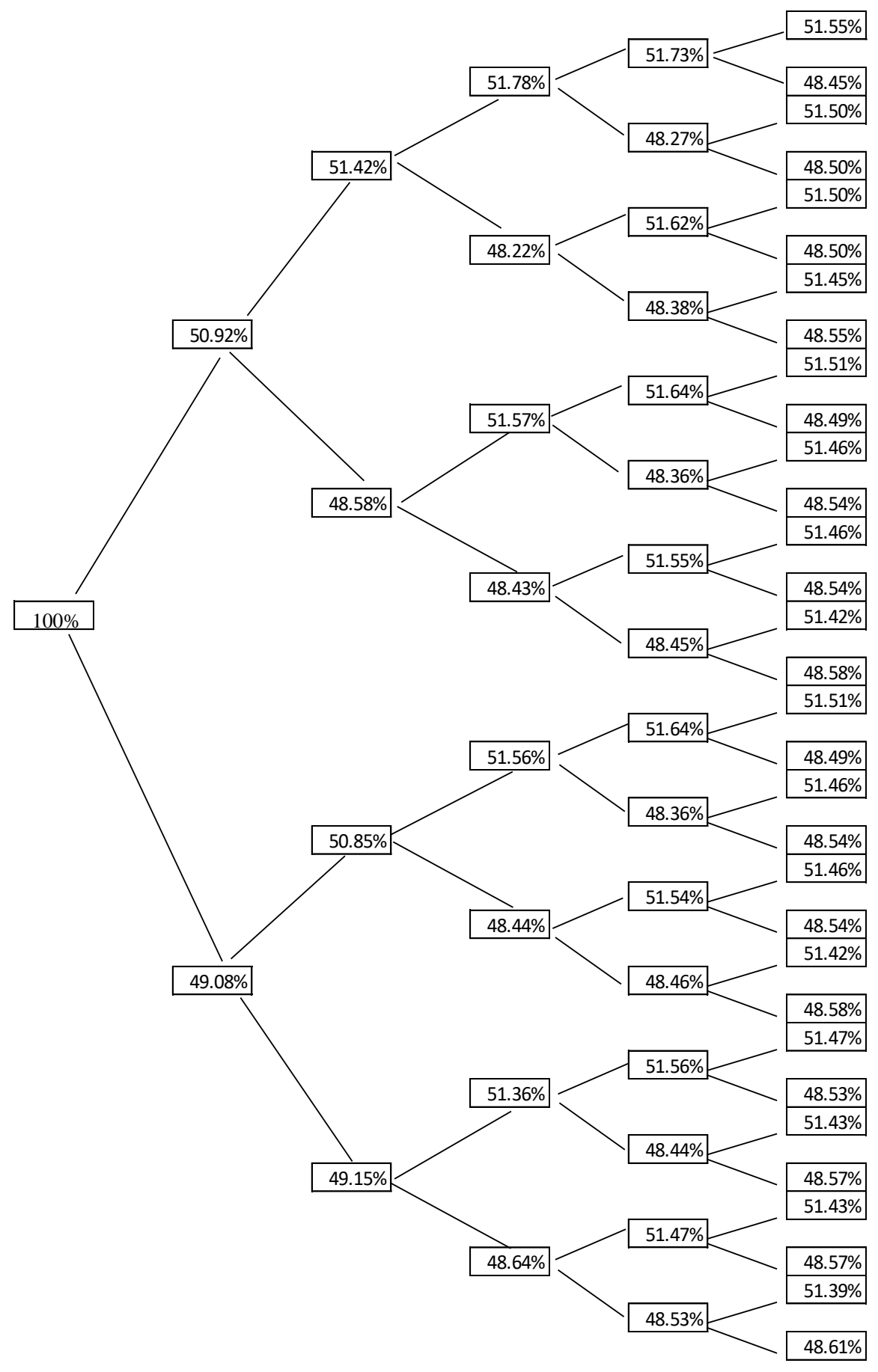

Figure 16: New path probabilities 
As mentioned before, it is not possible to make further adjustments giving any weight to each path probability as was done in a recombining binomial tree. The reason is because there is just one path to reach each node in a non-recombining binomial tree. The construction of a general implied binomial tree developed by Jackwerth (1994), and the weight function algorithms presented by Lim and Zhi (2002) can just be applied to the recombining binomial trees.

Now, it is time to get the current project value without options with the new adjusted path probabilities. As one can see, there is just a slightly difference between the project equity value found in a non-recombining tree, which is $\$ 10.09$; and the value found in a recombining binomial tree, which it was $\$ 10.12$. The results are shown in figure 17. 


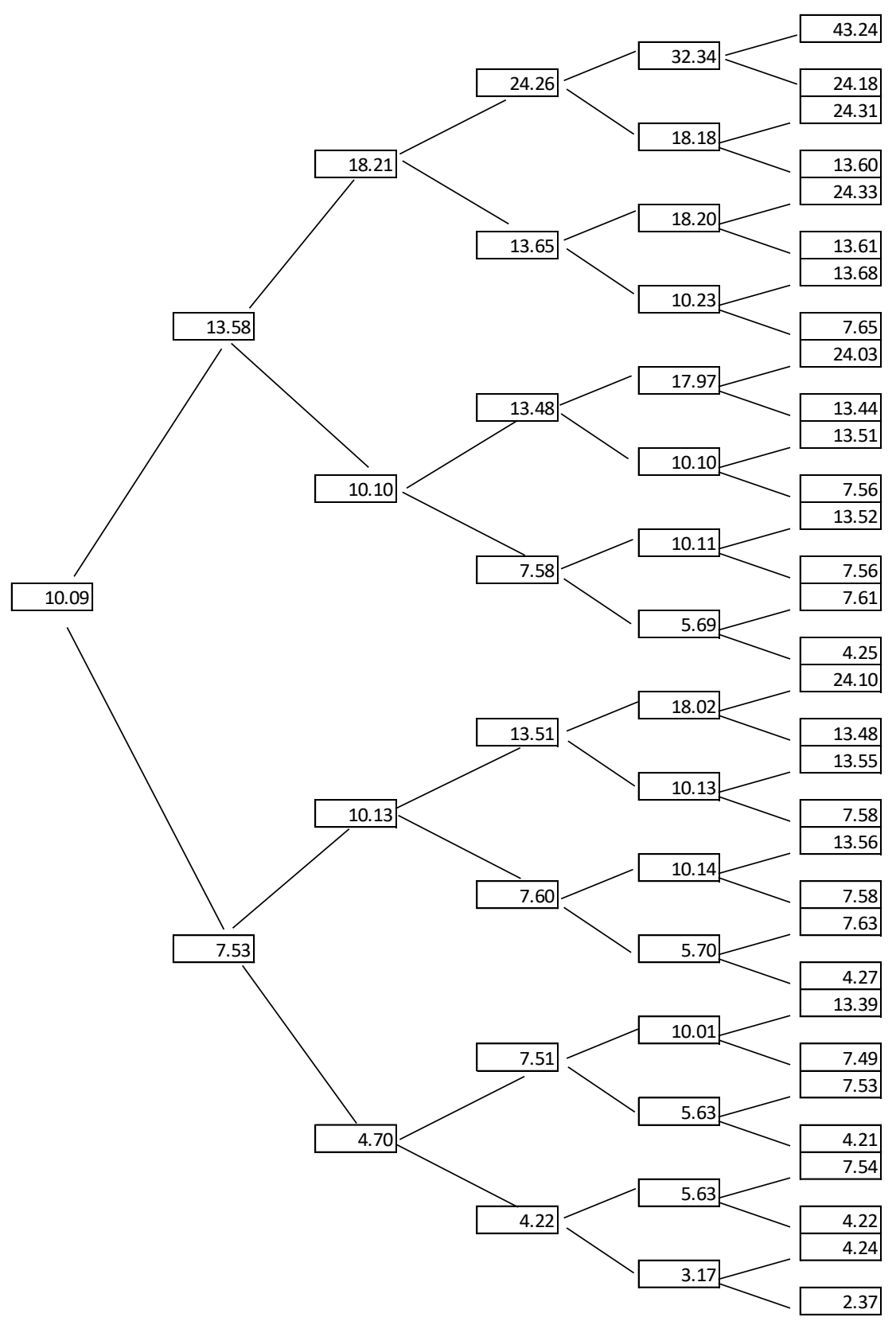

Figure 17: Simulated project value with adjustments

As in the previous case, the project has two options during its life: selling the project participation at the end of any year and expand the project at the end of year five. The project can be sold by USD 7,00.00 million, which it turns to be USD 8.92 each stock. The option to expand will increase value in 50\%, but an investment of USD 3,000.00 million must be done. In this case, the stock value will depend of each nodal value. The following table presents the project value taking in consideration only the option to expand at the end of year five. 


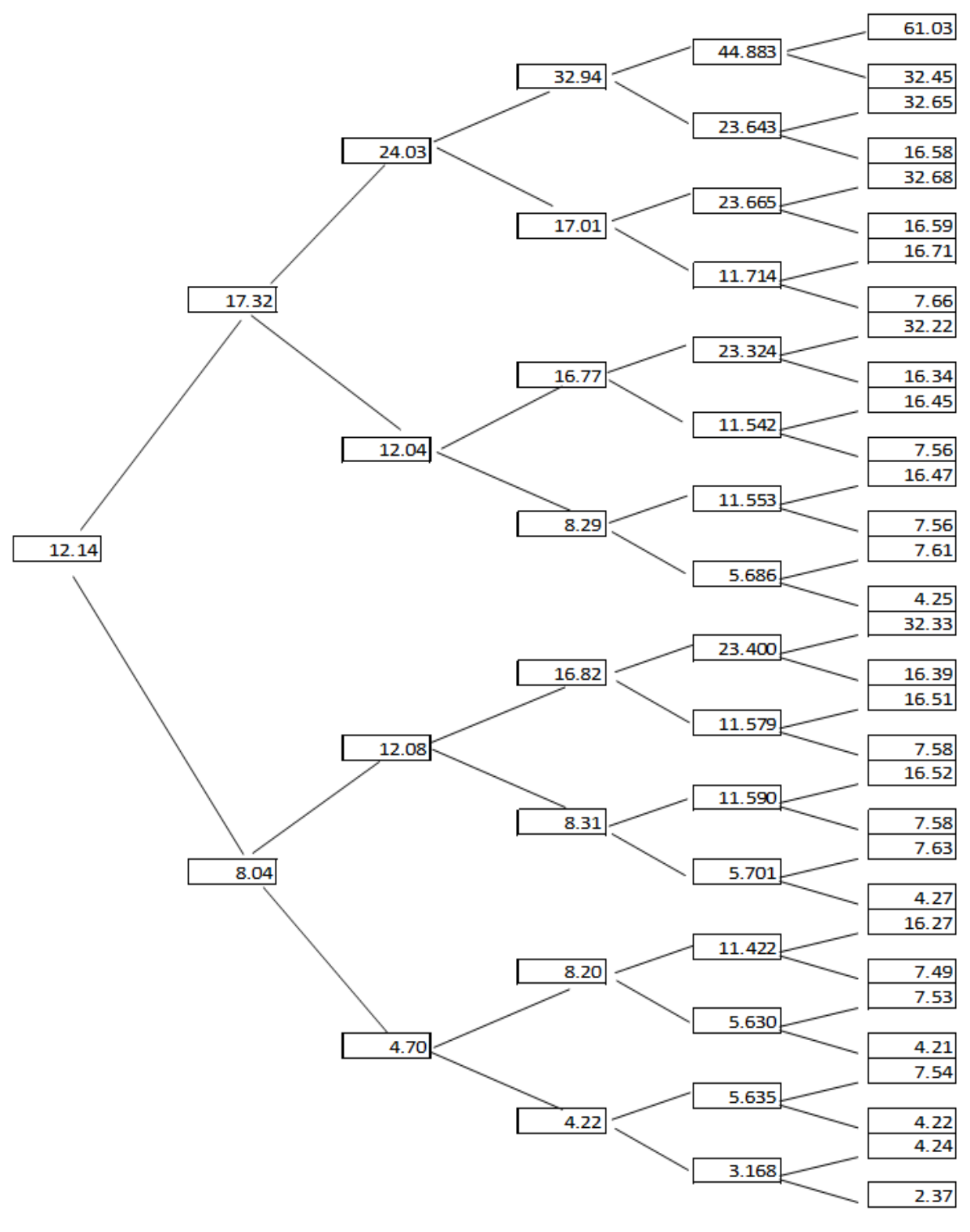

Figure 18 - Project value with option to expand

As seen in Figure 18, the current project equity value is $20.31 \%$ more than before. Now, considering only the option to expand the project stock value is USD 12.14. When there was no any option the project stock value was USD 10.09, as shown in table 14. This will imply that the option to expand is worth USD 2.05 for each stock. Since there is assumed that there are 785 million shares, the option to expand contributes to increase project value in USD $1,609.25$ million $(785 \times 2.05)$

When the project only considers the option to abandon, the value increase to USD 10.94, which is $8.4 \%$ more than the project without options, as shown in Figure 19. 

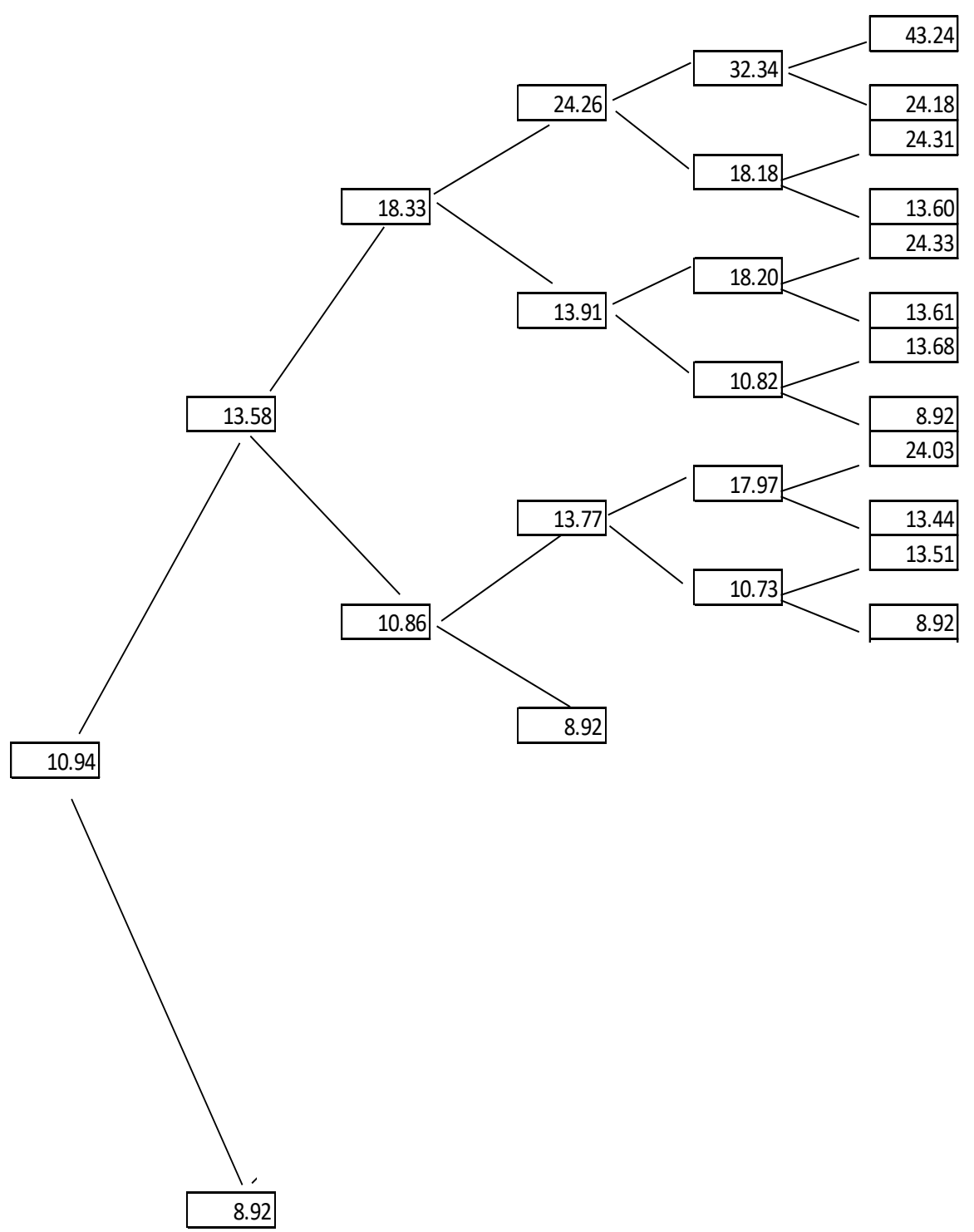

Figure 19 - Project value with option to abandon

This means that the option to abandon is worth USD 0.85 per each share, or USD 667.25 million dollars.

Finally, when both options are included, the project equity value increases by $25.66 \%$, to USD 12.68, as shown in Figure 20. 


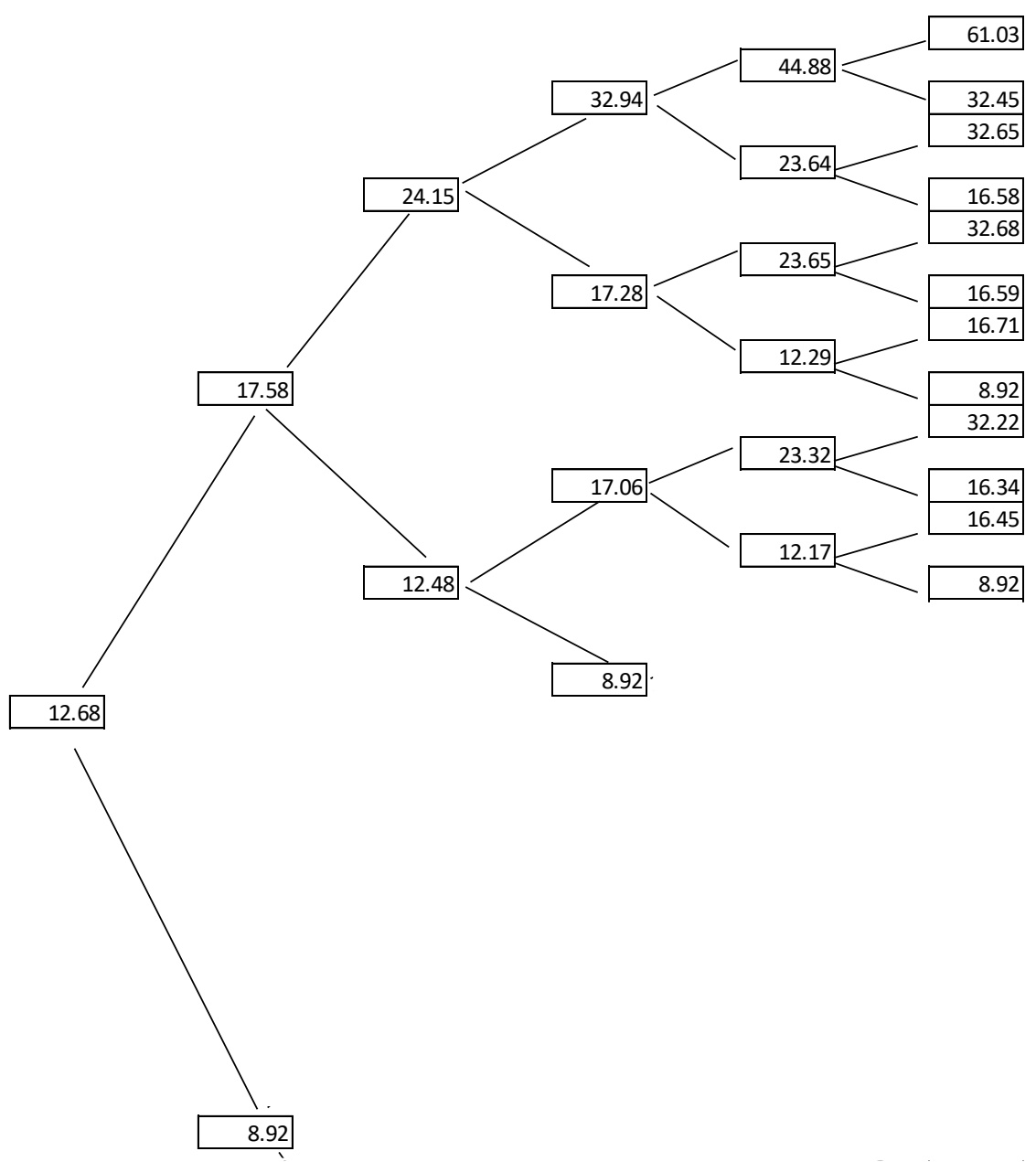

Figure 20 - Project value with option to abandon and expand

\section{3}

\section{Applied case using the traditional CRR binomial tree.}

The project return parameters to build the traditional CRR (1979) binomial tree are the same used to construct the recombining implied binomial tree described in section 4.1. In fact, table 3 shows project values for the five consecutive years and the initial nodal probabilities for each period.

The same options are considered in order value the managerial flexibility using the standard binomial tree. The results obtained will be compared to the ones previously obtained by the proposed model in this dissertation.

When the only the option to expand is exercised the project increase its value in $20.39 \%$, and the project stock value increase from USD 10.12 to USD 12.19 each, as shown in table 10 . The flexibility to expand increases project equity value 
to USD 9, 569.15 MM (USD12.19 $\times 785$ million shares). The option to expand is worth almost USD $1620 \mathrm{MM}$.

Table 10 - Project value with option to expand

\begin{tabular}{ccccccc} 
Project value & $\mathbf{0}$ & $\mathbf{1}$ & $\mathbf{2}$ & $\mathbf{3}$ & $\mathbf{4}$ & $\mathbf{5}$ \\
\hline & 12.19 & 13.16 & 14.18 & 15.28 & 16.46 & 17.73 \\
& & 10.89 & 11.90 & 12.83 & 13.83 & 14.91 \\
& & 8.92 & 10.70 & 11.55 & 12.47 \\
& & & & 9.57 & 10.34 \\
& & & & & 7.88 & 8.49 \\
& & & & & & 7.13
\end{tabular}

When only the option to abandon is exercised, the project stock value increases just in $0.12 \%$. This little change can be explained by the low assumed price to sell the mining project. Table 11 presents the project stock value when this option is exercised.

Table 11 - Project value with option to abandon -CRR

\begin{tabular}{ccccccc} 
Project value & $\mathbf{0}$ & $\mathbf{1}$ & $\mathbf{2}$ & $\mathbf{3}$ & $\mathbf{4}$ & $\mathbf{5}$ \\
\hline \multirow{2}{*}{10.13} & 10.86 & 11.65 & 12.49 & 13.40 & 14.37 \\
& 9.46 & 10.13 & 10.86 & 11.65 & 12.49 \\
& & & 9.46 & 10.12 & 10.86 \\
& & & & & 9.44
\end{tabular}

Since the option to abandon increases very little value, when applying the both options at the same time, the value increases almost to the same value as when just the option to expand is applied. The project stock value is USD 12.19 as in the first case. Table 12 presents the project values for each node when both options are exercised.

Table 12 - Project value with option to abandon and expand -CRR

\begin{tabular}{ccccccc} 
Project value & $\mathbf{0}$ & $\mathbf{1}$ & $\mathbf{2}$ & $\mathbf{3}$ & $\mathbf{4}$ & $\mathbf{5}$ \\
\hline \multirow{2}{*}{12.19} & 13.16 & 14.18 & 15.28 & 16.46 & 17.73 \\
& & 10.88 & 11.88 & 12.83 & 13.83 & 14.91 \\
& & & 10.61 & 11.55 & 12.47 \\
& & & & & & 10.34
\end{tabular}


It is interesting to compare the results obtained from the model application to the ones got from standard binomial tree. Table 13 presents a comparison of these results for the implied recombining tree (IRT) and implied non recombining tree (INRT) adjusted by skewness and kurtosis, and the results from the standard binomial tree (CRR).

Table 13 - Comparison of project values

\begin{tabular}{|c|c|c|c|}
\hline Project stock values & IRT & INRT & CRR \\
\hline Project stock value without options & 10.09 & 10.09 & 10.12 \\
\hline Project stock value with option to expand & 12.16 & 12.14 & 12.19 \\
\hline Project stock value with option to abandon & 10.17 & 10.94 & 10.13 \\
\hline $\begin{array}{l}\text { Project stock value with option to expand and } \\
\text { abandon }\end{array}$ & 12.22 & 12.68 & 12.19 \\
\hline
\end{tabular}

As table 13 shows, the initial project stock values in the implied trees are slightly lower than the one found in the CRR tree; this can be explained by the probability adjustment made by skewness and kurtosis. Since in both cases, the sum of the adjusted probabilities was not $100 \%$, an adjustment had to be done to as explained in the previous chapter. This is the reason for that little difference.

Most of the project stock values with options in the implied trees are greater than in the standard binomial tree. The explanation for this is basically the weight given to the upward paths in the implied binomial trees. As explained before, when a function of weight is applied to a path tree, it is possible to change these path probabilities in order to make the upward scenarios more probable applying the analyst criteria due to some information processed by him. Only in the option to expand the CRR tree presents a greater value, USD 12.19 against USD 12.16 and USD 12.14 in the IRT and INRT respectively. This can be explained by the probability adjustment made considering the level of skewness and kurtosis. As explained before, when the project return is not totally normal distributed, which means it has certain level of skewness and a kurtosis greater than three, the lower future values are more probable, such in the case presented in this application. However this consideration can be compensated with some weight distribution 
given in path probabilities, as in the option to abandon in the IRT. The option to abandon in the INRT gives more value because of the more case scenarios of project continuity this tree has. In a non-recombining implied tree, there are more scenarios where the project can continue and have greater values because of changing volatility, and the option to abandon is not exercised. 


\section{5 \\ Conclusions}

This dissertation develops a novel approach to assess investment projects by adjusting project values by its return's skewness and kurtosis. These parameters are usually not considered when assessing projects, even when they are analyzed using real options theory. These parameters can help to provide a better project risk measure, since they generate more accurate probabilities for project future values. This work also includes managerial flexibility by taking into account some decisions than can alter project values, such as the option to sell or to expand. The conclusions obtained by this work are detailed below.

- The proposed model allows firms to assess projects whose returns depart from being normally distributed, since its return's skewness and kurtosis can be different from zero and greater than three respectively. In this work, we present an equation to determine project value, which follows a lognormal distribution. However, its annualized yield can depart a little from being normally distributed in terms of skewness and kurtosis values. The project value which can be adjusted by a lognormal distribution will have zero skewness and a three-kurtosis value. As shown in the applied case, the project return can deviate from being normally distributed because of the random behavior of project values.

- The level of project return's skewness and kurtosis can allow to determine how likely would be the probability of obtaining low project values or high project values; depending on positive or negative skewness respectively. As seen in the applied case shown in this work, the project return has a positive skewness, which suggests a more likely scenario of having lower future values.

- The use of implied binomial trees allows having a better model to analyze project values under a managerial flexibility approach. There are different ways to model project values, but binomial trees permit to consider the exercise of any option at any time and also to incorporate several options at the same time. Being more specifically, implied binomial trees allows to 
distribute probabilities values (nodal or path probabilities) under some considerations, such as the level of skewness and kurtosis, and weight functions depending on if they are applied to a recombining or nonrecombining binomial trees. In this work two cases are analyzed: a recombining and non- recombining binomial tree model.

- The Gram Charlier expansion can be used to adjust ending nodal probabilities in binomial trees to incorporate another indicators of risks, such as project return's skewness and kurtosis. The Gram Charlier expansion serves to treat project asset returns that are not normally distributed and are leptokurtic. As mentioned before, when the project has negative skewness and a kurtosis greater than three means that lower values are more likely than higher future values. As shown in the applied case, lower project values are more likely than higher project values, since low nodal probabilities are higher than the upper ones.

- Weight functions are mostly used for recombining binomial trees. Most of the project values are modeled using binomial trees considering constant volatility, which generates a recombining binomial tree. A weight function to construct a general implied binomial tree can be used only because there are several paths to get the same project value, so there are different weights that can be applied to these paths to obtain the same future value, or the initial value, considering the project value without options. As shown in this work, a weight function to build a general implied tree allows obtaining the same initial value, although greater probabilities to lower future values had been given.

- The inclusion of managerial flexibility, as the way of real options theory permits, provides greater project values. It is well known that when there is more uncertainty and flexibility, real options increase the underlying asset value, in this case project values. In both models presented in this work, recombining and non-recombining binomial trees, the inclusion of real options increase project value in $21.11 \%$ and $25.66 \%$ respectively.

Adjusting probabilities by Gram Charlier expansion, gives the possibility to adjust probabilities of different scenarios considering a new risk indicators: project 
return's skewness and kurtosis. This allows us to develop a valuation method that combines real option analysis and implied binomial trees. The model can be more accurate when valuing a project that list in the stock market and has traded financial options. In the presented applied case the results indicate that the company is 25.66 $\%$ undervalued when taking in consideration real options in a non-recombining binomial tree, which means non constant volatility.

Some simple examples of options that companies could take would be the extension of a project, acquisition or merger of a company, the closure or sale of a business unit, or simply the delay of programmed investment in a given project. These ranges of options are not considered in traditional methodologies, and therefore the added value or loss of value is not considered within the estimated market value.

This work shows that using changing volatility obtained from Monte Carlo simulations is appropriate because it reflects market uncertainty regarding the company real value. Traditional methodologies for valuing businesses, such as NPV, do not incorporated, not model the potential uncertainties in projects or activities of the companies.

Implied general trees adjusted by skewness and kurtosis allow the inclusion of analyst input into the valuation process but considering uncertain scenarios, especially when short periods of time are considered. The combination of constructing a forward binomial tree, based on volatility; and then get a general tree, based on the judgment of the analyst and the real options approach allows to obtain better and more accurate evaluation tool to model project uncertainties for taking decisions.

One of the limitations of this work is that the proposed model can be only applied to projects whose return has unimodal probability distributions. Another limitation is that the application of the proposed model is more suitable for projects whose value depends on liquid assets, such as commodity prices. The proposed model would be difficult to apply in sectors where the underlying assets have no market value, or there are no free access information. Other limitation could be the suitability of this model to assess projects with more time life since more 
computational effort will be required, specially using the non-recombining threes proposed in this dissertation.

Future research can consider the analysis of other variables such as, operation costs, production, reserves estimation and even some social issues regarding project valuation. It would be also interesting considering other stochastic process, such as Mean Reversion, to measure the impact on project valuation; and the application on other sectors, such as agriculture and energy. 


\section{6 \\ References}

AJAK, A. D.; TOPAL, E. Real option in action: An example of flexible decision making at a mine operational level. Resources Policy, v. 45, p. 109-120, 2015.

BARLE, S., CAKICI, N. How to Grow a Smiling Tree. Journal of Financial Engineering, v. 7 (2), p. 127-146, 1998.

BLACK, F., SCHOLES, M. The Pricing of Options and Corporate Liabilities. The Journal of Political Economy, v. 81(3), p. 637-654, 1973.

BRANDÃO, L. E., DYER, J. S., \& HAHN, W. J. Using binomial decision trees to solve real option valuation problems. Decision Analysis, v. 2, p. 69-88, 2005.

BRANDÃO, L. E., DYER, J. S., HAHN, W. J.. Volatility estimation for stochastic project value models. European Journal of Operational Research, 220 (3), p. 642-648, 2012. doi: 10.1016/j.ejor.2012.01.059

BRENNAN, M. J., SCHWARTZ, E. S. Evaluating Natural Resource Investments. Journal of Business, v. 58(2), p. 135-157, 1985.

CHOI, P.; NAM, K. Asymmetric and leptokurtic distribution for heteroscedastic asset returns: The $\mathrm{S}_{\mathrm{U}}$-normal distribution. Journal of Empirical Finance, v 15 (1), p. 41-63, 2008.

COPELAND, T.; ANTIKAROV,V. Real options: a practitioners guide. Texere Publishing, 2001.

COX, C., ROSS, S., RUBINSTEIN, M. Option pricing: A simplified approach. Journal of Financial Economics, v. 7 (3), p. 229-263, 1979.

CHARALAMBOUS, C. et al. Implied non-recombining trees and calibration for the volatility smile. Quantitative Finance, v. 7 (4), p. 459-472, 2007.

DERMAN, E., KANI, I. Riding on a smile. Risk 7, v. 2, p. 32-39, 1996.

DICKEY, D., FULLER, W. Distribution of the estimators for autoregressive time series with a unit root. Journal of the American Statistical Association, v. 74 (366),p. 427-431, 1979

DIMITRAKOPOULOS, R. G., ABDEL SABOUR, S. A. Evaluating mine plans under uncertainty: Can the real options make a difference? Resources Policy, v. 32(3),p. 116-125, 2007

DIXIT, A. K., PINDYCK, R. S. Investment under Uncertainty. Princeton: Princeton University Press, 1994.

FRIMPONG, S., WHITING, J. M. Derivative mine valuation: strategic investment decisions in competitive markets. Resources Policy, v. 23(4), p. 163-171,1997 
GIBSON, R., SCHWARTZ, E. S. Stochastic Convenience Yield and the Pricing of Oil Contingent Claims. Journal of Finance, v. 45(3),p. 959-976, 1990.

GODINHO, P. Monte Carlo estimation of project volatility for real option analysis. Journal of Applied Finance, v. 16(1),p. 15-30, 2006.

HAQUE, M. A., TOPAL, E., LILFORD, E. A numerical study for a mining project using real options valuation under commodity price uncertainty. Resources Policy, 39, 115-123, 2014.

HUMPHREYS, D. New approaches to valuation: a mining company perspective: Valuing risk and flexibility: a comparison of methods (by Nathalie Moyen, Margaret Slade and Raman Uppal). Resources Policy, v. 22(1-2),p. 75-77, 1996.

INTHAVONGSA, I., DREBENSTEDT, C., BONGAERTS, J., \& SONTAMINO, P. Real options decision framework: Strategic operating policies for open pit mine planning. Resources Policy, v. 47, p. 142-153, 2016.

JACKWERTH, J. Generalized binomial trees. The Journal of Derivatives, v.5 (2) , p. $7-17,1997$.

JONDEAU, E., ROCKINGER, M. Conditional volatility, skewness and kurtosis: existence, persistence, and comovements. Journal of Economic Dynamics and Control, v 27 (10), p. 1699-1737, 2003.

KELLY, S. A binomial lattice approach for valuing a mining property IPO. The Quarterly Review of Economics and Finance, v. 38(3, Part 2), p. 693-709, 1998.

KOUSHAVAND, B., ASKARI-NASAB, H., \& DEUTSCH, C. V. A linear programming model for long-term mine planning in the presence of grade uncertainty and a stockpile. International Journal of Mining Science and Technology, v. 24(4), p. 451-459, 2014

LIM, K., ZHI, D. Pricing options using implied trees: Evidence from FTSE - 100 Options, Journal of Futures Markets, v. 22 (7) , p.601-628, 2002

MARDONES, J. Option valuation of real assets. Resources Policy, v. 19 (1), p. 51-65, 1993.

MARTINEZ, L. Coal Mine Project Evaluation Using an Integrated Real Options Model Approach. Mineralproduksjon, v. 2, p. 31-52, 2012.

MCDONALD, R., SIEGEL, D. The Value of Waiting to Invest. Quarterly Journal of Economics, v. 101(4), p. 707-728, 1986.

MERTON, R. C. Theory of Rational Option Pricing. The Bell Journal of Economics and Management Science, v. 4(1), p. 141-183, 1973.

MIRANDA,O., BRANDÃO, L. E., LAZO, JUAN. A dynamic model for valuing flexible mining exploration projects under uncertainty. Resources Policy, v. 52, p. 393-404, 2017. 
MITTNIK, S., PAOLELLA, M.S., RACHEV, S.T. Diagnosing and treating the fat tails in financial returns data, Journal of Empirical Finance, v. 7 p. 389-416, 2000.

MOEL, A., TUFANO, P. When Are Real Options Exercised? An Empirical Study of Mine Closings. Review of Financial Studies, v. 15(1), p. 35-64, 2002.

MOYEN, N., SLADE, M., UPPAL, R. Valuing risk and flexibility: A comparison of methods. Resources Policy, v. 22 (1-2), p. 63-74, 1996

MYERS, S. Determinants of corporate borrowing. Journal of Financial Economics, v. 5, p. 145-175, 1977.

OZORIO, L. D. M., BASTIAN-PINTO, C. D. L., BAIDYA, T. K. N., \& BRANDÃO, L. E. T. Investment decision in integrated steel plants under uncertainty. International Review of Financial Analysis, v. 27(0), p. 55-64, 2013.

RUBINSTEIN, M. Implied binomial trees. The journal of Finance, v. 49 (3), p. 771-818, 1994

RUBINSTEIN, M. Edgeworth Binomial Trees. Journal of Derivatives, v. 5, p. 20 27, 1998.

SCHWARTZ, E., SMITH, J. E. Short-Term Variations and Long-Term Dynamics in Commodity Prices. Management Science, v. 46(7), p. 893-911, 2000.

SCHWARTZ, E. S. The Stochastic Behavior of Commodity Prices: Implications for Valuation and Hedging. Journal of Finance, v. 52(3),p. 923-973, 1997.

SHAFIEE, S., TOPAL, E., \& NEHRING, M. Adjusted Real Option Valuation to Maximise Mining Project Value - A Case Study Using Century Mine. In Project Evaluation Conference, Melbourne, Victoria, p.125-134, 2009.

SLADE, M. E. Valuing Managerial Flexibility: An Application of Real-Option Theory to Mining Investments. Journal of Environmental Economics and Management, v. 41(2), p. 193-233, 2001.

TIRANTIS, A., BORISON, A. Real options: State of practice. Journal of Applied Corporate Finance, v 14, p. 8-24, 2001.

TOURINHO, O. A. F. The valuation of reserves of natural resources: an option pricing approach. Doctoral PhD Dissertation, University of California, Berkeley, 1979.

TRIGEORGIS, L. Real options, Managerial Flexibility and Strategy in Resources Allocation. Cambridge, Massachussets: MIT Press, 1996.

WANG, T., DYER, J. Valuing multifactor real options using an implied binomial tree. Decision Analysis, v. 7 (2), p. 185-195, 2010. 


\section{Annexes}

Annex 1: Simulated and expected free cash flow (USD mm).

\begin{tabular}{|c|c|c|c|c|c|c|}
\hline Simulation & 0 & 1 & 2 & 3 & 4 & 5 \\
\hline S1 & 2500.00 & 3139.58 & 3362.09 & 4051.94 & 4689.92 & 3402.96 \\
\hline S2 & 2500.00 & 2698.73 & 3035.11 & 2372.63 & 2514.18 & 4713.42 \\
\hline S3 & 2500.00 & 3534.96 & 3659.36 & 5594.63 & 4126.86 & 2345.52 \\
\hline S4 & 2500.00 & 1799.77 & 2098.92 & 1602.37 & 1092.86 & 1190.23 \\
\hline S5 & 2500.00 & 2543.98 & 2588.74 & 2634.29 & 2680.63 & 2727.79 \\
\hline
\end{tabular}

The table above presents the cash flows obtained from equation (9), where K $=30 \%$, considering a random behavior from year 1 to year 5 . The table below represents the simulated project expected value from year 1 to year 5. As seen in Table 2, in year 0 the expected project value is known, because the initial free cash flow is also known. However, for the following years, the expected project values are calculated using Monte Carlo simulations.

\begin{tabular}{lcccccc}
\multicolumn{1}{c}{ Year } & $\mathbf{0}$ & $\mathbf{1}$ & $\mathbf{2}$ & $\mathbf{3}$ & $\mathbf{4}$ & $\mathbf{5}$ \\
\hline Sim. EV (USD mm) & 10,278 & 10313 & 13890 & 12262 & 14661 & 19195 \\
Exp. EV (USD mm) & $\mathbf{1 0 , 2 7 8}$ & $\mathbf{1 0 7 6 0}$ & $\mathbf{1 1 2 0 7}$ & $\mathbf{1 1 6 9 3}$ & $\mathbf{1 2 2 0 9}$ & $\mathbf{1 2 7 1 7}$ \\
Debt/Equity & 0.23 & 0.23 & 0.23 & 0.23 & 0.23 & 0.23 \\
Equity Value (USD mm) & $\mathbf{\$ 7 , 9 4 7}$ & $\mathbf{8 3 2 0}$ & $\mathbf{8 6 6 5}$ & $\mathbf{9 0 4 1}$ & $\mathbf{9 4 4 0}$ & $\mathbf{9 8 3 3}$ \\
Shares (in millions) & 785 & $\mathbf{7 8 5}$ & $\mathbf{7 8 5}$ & $\mathbf{7 8 5}$ & $\mathbf{7 8 5}$ & $\mathbf{7 8 5}$ \\
\cline { 2 - 7 } Stock price & $\mathbf{\$ 1 0 . 1 2}$ & $\mathbf{1 0 . 1 6}$ & $\mathbf{1 3 . 6 8}$ & $\mathbf{1 2 . 0 8}$ & $\mathbf{1 4 . 4 4}$ & $\mathbf{1 8 . 9 1}$
\end{tabular}

